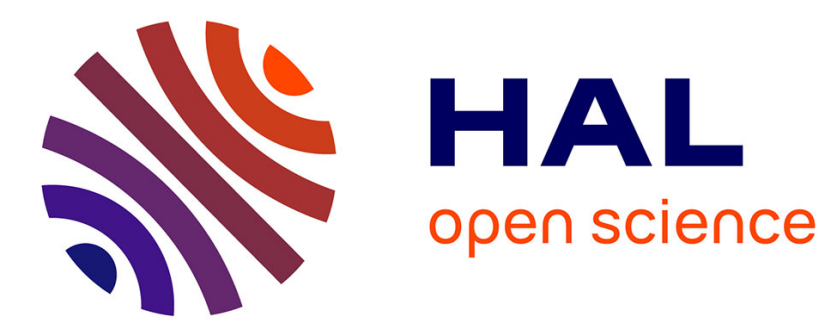

\title{
TReacLab: An object-oriented implementation of non-intrusive splitting methods to couple independent transport and geochemical software
}

Daniel Jara, Jean-Raynald de Dreuzy, Benoit Cochepin

\section{To cite this version:}

Daniel Jara, Jean-Raynald de Dreuzy, Benoit Cochepin. TReacLab: An object-oriented implementation of non-intrusive splitting methods to couple independent transport and geochemical software. Computers \& Geosciences, 2017, 109, pp.281-294. 10.1016/j.cageo.2017.09.005 . insu-01588325

HAL Id: insu-01588325

https://hal-insu.archives-ouvertes.fr/insu-01588325

Submitted on 15 Sep 2017

HAL is a multi-disciplinary open access archive for the deposit and dissemination of scientific research documents, whether they are published or not. The documents may come from teaching and research institutions in France or abroad, or from public or private research centers.
L'archive ouverte pluridisciplinaire $\mathbf{H A L}$, est destinée au dépôt et à la diffusion de documents scientifiques de niveau recherche, publiés ou non, émanant des établissements d'enseignement et de recherche français ou étrangers, des laboratoires publics ou privés. 


\section{Accepted Manuscript}

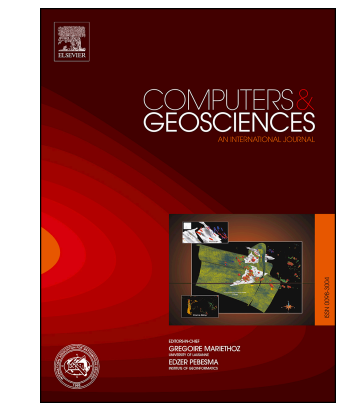

TReacLab: An object-oriented implementation of non-intrusive splitting methods to couple independent transport and geochemical software

Daniel Jara, Jean-Raynald de Dreuzy, Benoit Cochepin

PII: S0098-3004(17)30251-0

DOI: $\quad$ 10.1016/j.cageo.2017.09.005

Reference: CAGEO 4019

To appear in: Computers and Geosciences

Received Date: 6 March 2017

Revised Date: 1 September 2017

Accepted Date: 7 September 2017

Please cite this article as: Jara, D., Dreuzy, J.-R.d., Cochepin, B., TReacLab: An object-oriented implementation of non-intrusive splitting methods to couple independent transport and geochemical software, Computers and Geosciences (2017), doi: 10.1016/j.cageo.2017.09.005.

This is a PDF file of an unedited manuscript that has been accepted for publication. As a service to our customers we are providing this early version of the manuscript. The manuscript will undergo copyediting, typesetting, and review of the resulting proof before it is published in its final form. Please note that during the production process errors may be discovered which could affect the content, and all legal disclaimers that apply to the journal pertain. 
1 TReacLab: an object-oriented implementation of non-intrusive

2 splitting methods to couple independent transport and geochemical

3 software

4 Daniel Jara ${ }^{1}$, Jean-Raynald de Dreuzy ${ }^{1}$, Benoit Cochepin ${ }^{2}$

$5{ }^{1}$ Géosciences Rennes, UMR CNRS 6118, Campus de Beaulieu, University of Rennes 1,

6 Rennes, France

$7 \quad$ 22ANDRA, 1/7 Rue Jean Monnet, 92298 Châtenay-Malabry, France

8 Abstract

9 Reactive transport modeling contributes to understand geophysical and geochemical processes

10 in subsurface environments. Operator splitting methods have been proposed as non-intrusive

11 coupling techniques that optimize the use of existing chemistry and transport codes. In this

12 spirit, we propose a coupler relying on external geochemical and transport codes with

13 appropriate operator segmentation that enables possible developments of additional splitting

14 methods. We provide an object-oriented implementation in TReacLab developed in the

15 MATLAB environment in a free open source frame with an accessible repository. TReacLab

16 contains classical coupling methods, template interfaces and calling functions for two

17 classical transport and reactive software (PHREEQC and COMSOL). It is tested on four

18 classical benchmarks with homogeneous and heterogeneous reactions at equilibrium or

19 kinetically-controlled. We show that full decoupling to the implementation level has a cost in

20 terms of accuracy compared to more integrated and optimized codes. Use of non-intrusive

21 implementations like TReacLab are still justified for coupling independent transport and

22 chemical software at a minimal development effort but should be systematically and carefully

23 assessed. 
24 Keywords: Porous media; Reactive transport; Operator splitting; Object-oriented

25 programming.

Corresponding author: daniel.jara.heredia@gmail.com

\section{Introduction}

The fate of chemical species in geological media results from the interaction of physical transport and chemical reactivity (Steefel et al., 2005). Understanding how they interact requires field and laboratory studies as well as numerical models. Numerical models are important for building predictive scenarios where experiments are limited spatially and temporally, as in long-term nuclear waste disposal assessment (Marty et al., 2014; Thouvenot et al., 2013; Trotignon et al., 2007). On the physical transport side, extensive work in applied mathematics and computational science has provided widely-used software for single and multi-phase flows as well as transport of chemical species such as MODFLOW (McDonald and Harbaugh, 1988), MT3DMS (Zheng and Wang, 1999), HYDRUS (Kool and Van Genuchten, 1991), COMSOL (COMSOL, 2010), FEFLOW (Diersch, 1996), MRST (Lie, 2014), and TOUGH2 (Pruess et al., 1999). On the chemistry side, geochemical software have implemented a wide range of chemical functions and reactions, including equilibrium aqueous speciation, equilibrium mineral dissolution/precipitation, gas phase exchange, ion exchange, redox reactions, and kinetic reactions. Some of these software are PHREEQC (Parkhurst and Appelo, 1999), GEMS (Kulik et al., 2013), CHEPROO (Bea et al., 2009), MINTEQ (Peterson et al., 1987), CHESS (Van der Lee, 2002), and Geochemist's Workbench (Bethke, 2007).

To combine physical and chemical reactivity, couplers have been developed between transport and geochemical codes such as PHAST for coupling HST3D and PHREEQC (Parkhurst et al., 2004), HP1 for HYDRUS and PHREEQC (Šimůnek et al., 2006), PHT3D 
for MT3DMS and PHREEQC (Prommer et al., 1999), HYTEC for RT1D/R2D2/METIS and

CHESS (van der Lee et al., 2003), OpenGeoSys-GEMS (Kulik et al., 2013) and iCP for

COMSOL and PHREEQC (Nardi et al., 2014), UTCHEM-IPhreeqc and

UTCHEM-EQBATCH (Kazemi Nia Korrani et al., 2015, 2016), multicomponent transport

software-IPhreeqc (Muniruzzaman and Rolle, 2016), FEFLOW-IPhreeqc (MIKE(DHI), 2016), Lattice Boltzmann transport software-IPhreeqc (Patel et al., 2013). Most of the previously cited codes have embedded the coupling method with the geochemical and transport methods to enhance global performance and reliability. Here, in order to gain flexibility, we propose in our code TReacLab a complementary development in the form of an ensemble of Operator Splitting methods (OS) with a generic set of interfaces to transport and reaction operators. In this context, OS decouples chemistry from transport as opposed to global implicit solvers, which have been proven to be more accurate but less flexible (Hammond et al., 2012; Hammond et al., 2014; Mayer, 2000; Steefel, 2009; Zhang, 2012). TReacLab is designed as an open toolbox where additional OS techniques can be implemented and benchmarked. Other transport and geochemical codes may also be used at the minimal cost of developing the necessary interfaces. TReacLab is written in MATLAB based on a series of abstract classes using object-oriented programming (Commend and Zimmermann, 2001; Register, 2007; Rouson et al., 2011).

After recalling in section 2 the reactive transport and OS formalism used, we present in section 3 our OS implementation. We especially show how to implement alternative OS methods and how to connect other transport and geochemical codes. Methods are assessed and discussed on the basis of 3 benchmarks in section 4 . 


\subsection{Reactive transport equation}

72 The reactive transport equation can be written in a general way as (Saaltink et al., 1998):

$$
\frac{\partial \theta_{c}}{\partial t}=M L(c)+\theta S_{i}^{t} r_{k}+\theta S_{k}^{t} r_{k}+Q
$$

73 where $c$ is the vector of concentrations for $N_{s}$ chemical species in the system. $\theta$ is a diagonal only single-phase flow:

$$
L(c)=\nabla \cdot[\mathbf{D} \nabla c-\theta v c]
$$

$81 \mathbf{D}\left(\mathrm{L}^{2} \mathrm{~T}^{-1}\right)$ is the effective dispersion-diffusion tensor (Bear, 1972). The velocity $\boldsymbol{v}\left(\mathrm{LT}^{-1}\right)$ is computed in a pre-processing phase, which can be decoupled from the reactive transport problem as long as hydraulic properties are not modified by the chemical reactivity. The

$$
\emptyset_{0}(c)=0
$$


and of the $N_{k}$ kinetically-controlled reactions:

$$
r_{k}=\emptyset_{k}(c)
$$

86 The reactive transport problem is thus made up of the $N_{s}$ mass balance equation (1) and of the

$87 N_{e}+N_{k}$ equilibrium and kinetic equations (3) and (4). Its unknowns are the concentrations $c$

88 and the reaction rates $r_{e}$ and $r_{k}$. The chemical equilibrium system (3) is composed of the 89 conservation equation and of the mass action law, relating reactants and products (Apoung90 Kamga et al., 2009; Molins et al., 2004):

$$
S_{t} \log (c)=\log (K)
$$

91 where $K$ is the vector of equilibrium constants.

92 Components $u$ are generally introduced when considering equilibrium reactions (Saaltink et 93 al., 2011):

$$
u=U c
$$

94 where $U$ is the component matrix (Fang et al., 2003; Friedly and Rubin, 1992; Hoffmann et 95 al., 2012; Kräutle and Knabner, 2005; Steefel et al., 2005). They are $N_{s}-N_{e}$ linear 96 combinations of chemical species that are not modified by equilibrium reactions (Molins $e t$ 97 al., 2004; Morel and Hering, 1993):

$$
U S_{\theta}^{t} r_{\theta}=0
$$


98 The component matrix is not unique. However, its application to equation (1) always leads to

99 a reduced system without the equilibrium rates but with the components $u$ (Molins et al., 100 2004; Saaltink et al., 1998):

$$
\frac{\theta_{u}}{\partial t}=U M L(c)+U \theta S_{k}^{t} r_{k}+U Q
$$

101 The reactive transport problem is then made up of the $2 N_{s}-N_{e}+N_{k}$ equations (3-6) and (8)

102 for the same number of unknowns $u, c$ and $r_{k}$.

103 Under the assumption that solid species are not transported and all species have the same

104 diffusion coefficient (i.e. $U M L(c)=U L(u)$ ). Equation (8) classically gives the two following

105 formulations TC and CC (Amir and Kern, 2010):

TC:

$$
\frac{\partial_{u}}{\partial t}=L\left(u_{a}\right)+U \theta S_{k}^{t} r_{k}+U Q
$$

$\mathrm{CC}:$

$$
\frac{\partial u_{a}}{\partial t}+\frac{\partial u_{F}}{\partial t}=L\left(u_{a}\right)+U \theta S_{k}^{t} r_{k}+U Q
$$

106 where $u_{a}=U M c$ and $u_{f}=U(I-M) c$ are the aqueous and fixed components. In the TC

107 formulation, the fixed species concentration are deducted from the solution in the total

108 component concentration $(\mathrm{T})$ and the solute concentration $(\mathrm{C})$. In the $\mathrm{CC}$ formulation, the total component concentration is divided in aqueous and fixed components. 


\subsection{Usual first-order sequential non-iterative and iterative approaches}

111 In this section, we show how the reactive transport problem can be solved using independent

112 transport and chemical solvers. We distinguish the sequential non-iterative and iterative

113 approaches respectively based on TC and CC formulations. For the sequential non-iterative

114 approach, we extract from the TC formulation, the transport operator in which we keep the

115 sink/source term:-

$$
\frac{a u}{\partial t}=L\left(u_{a}\right)+U Q
$$

116 The chemical operator derives from equations (3-6), and (8). Note that it does not contain any

117 source/sink term, as it has been included in the transport equation:

$$
\begin{gathered}
\frac{\partial u}{\partial t}=u s_{k}^{t} r_{k} \\
r_{k}=\emptyset_{k}(c) \\
u=U c \\
\emptyset_{\theta}(c)=0 .
\end{gathered}
$$

118 This is still a system of $2 N_{s}-N_{e}+N_{k}$ equations for the same number of unknowns. This

119 decoupled system can be solved with the classical sequential non-iterative approach using an

120 explicit integration of temporal derivatives (herein, we assume forward Euler). The solution at

121 time step $n+1$ can be obtained from the solution at time step $n$, with the following successive

122 application of the transport and chemical operators in a sequential approach: 


$$
u^{*}=u_{n}+\Delta t\left(L\left(u_{a}\right)+U Q\right)
$$

$$
\left\{\begin{array}{c}
u^{*}=U c_{n+1} \\
\emptyset_{0}\left(c_{n+1}\right)=0
\end{array}\right.
$$

$$
\begin{gathered}
r_{k_{n+1}}=\emptyset_{k}\left(c_{n+1}\right) \\
u_{n+1}=u^{*}+\Delta t U S_{k}^{t} r_{k_{n+1}}
\end{gathered}
$$

123 The transport operator (11) is applied to the components. Then the chemical operator is

124 applied with the updated mobile components for speciation between fixed and solute

125 concentrations. In the specific case where chemical reactions are all at equilibrium and no

126 kinetics is involved, a TC formulation is used to fully decouple (de Dieuleveult et al., 2009).

127 In such case the decoupling does not then rely on operator splitting, but on a block

128 Gauss-Seidel method.When the stability conditions of the explicit integration are too much

129 constraining, implicit schemes should be used instead within a sequential iterative approach

130 (Carrayrou et al., 2004; de Dieuleveult and Erhel, 2010; Yeh and Tripathi, 1989):

$$
\begin{gathered}
u_{n+1}=u_{n}+\Delta t\left[L\left(u_{a_{n+1}}\right)+\theta S_{k}^{t} r_{k_{n+1}}+U Q\right] \\
\left\{\begin{array}{l}
u_{n+1}=U c_{n+1} \\
\emptyset_{\varepsilon}\left(c_{n+1}\right)=0
\end{array}\right. \\
r_{k_{n+1}}=\emptyset_{k}\left(c_{n+1}\right) .
\end{gathered}
$$

131 Classical Picard's method have been extensively used to solve such kind of problems: 


$$
u_{n+1}^{k+1}=u_{n}+\Delta t\left[L\left(u_{a_{n+1}}^{k+1}\right)+\theta S_{k}^{t} r_{k_{n+1}}^{k}+U Q\right]
$$

$$
\begin{gathered}
\left\{\begin{array}{l}
u_{n+1}^{k+1}=U c_{n+1}^{k+1} \\
\emptyset_{\theta}\left(c_{n+1}^{k+1}\right)=0
\end{array}\right. \\
r_{k_{n+1}^{k+1}}^{k+1}=\emptyset_{k}\left(c_{n+1}^{k+1}\right),
\end{gathered}
$$

132 where $k$ is the index of the Picard iteration method instantiated by:

$$
\begin{gathered}
u_{n+1}^{k=1}=u_{n} \\
r_{k_{n+1}}^{k=1}=r_{k_{n}} .
\end{gathered}
$$

133 We recall the necessity to check the consistency of the temporal integration scheme with the

134 Operator Splitting method chosen. With this decomposition, explicit first-order scheme

135 naturally leads to sequential non-iterative approach. The implicit first-order scheme requires a

136 sequential iterative approach. Other choices are possible and might reduce errors depending

137 on the chemical system (Barry et al., 1996). As it should be possible to test and benchmark

138 them at a reduced development cost, we use a generic decoupling formalism that can be used

139 to implement a broad range of schemes.

\subsection{Generic operator splitting implementation}

141 The reactive transport system can be generically split in two operators. Using the formalism

142 of Gasda et al. (2011), equation (1) can be written as: 


$$
\frac{\partial Z}{\partial t}=\mathcal{L}_{1} Z+\mathcal{L}_{2} Z, \quad Z(t=0)=Z_{0}, \quad 0 \leq t \leq T,
$$

143 where $Z$ is the unknown, $\mathcal{L}_{1}$ and $\mathcal{L}_{2}$ can be equation (11) and (12), respectively. Other

144 decomposition are possible, e.g. the transport operator can be subdivided into an advection 145 and a diffusion-dispersion operator (Clement et al., 1998), or one operator might contain 146 advection-reaction and the other diffusion (Liu and Ewing, 2005). Each operator will be

147 solved separately for a splitting time step $\Delta t=t^{n+1}-t^{n}$ using adapted numerical methods.

148 The generic operator splitting methods implemented into the Toolbox are the sequential 149 splitting, additive splitting, Strang splitting, symetrically weighted splitting, and alternating method (Appendix A). Assuming exact integration of the operators and homogeneous

151 boundary conditions in equation (18), the first two have a first-order temporal truncation 152 error, and the following three a second-order one (Hundsdorfer and Verwer, 2013). Since the 153 operators are usually solved using numerical methods, the global order of such approaches 154 might be modified because of the order of the numerical methods used for each operator 155 (Barry et al., 1996; Csomós and Faragó, 2008). The alternating splitting increases the order of 156 the sequential splitting if the time steps are small enough (Simpson and Landman, 2008; 157 Valocchi and Malmstead, 1992).

\section{Operator splitting implementation and software organization}

159 We provide in TReacLab an object-oriented toolbox for the non-intrusive operator splitting 160 methods of the previous section. TReacLab is organized along three main components for 161 coupling transport and reactivity, and proceeds in three pre-processing, processing and 162 post-processing phases (Figure 1). These three components correspond to the three 


\section{ACCEPTED MANUSCRIPT}

163 well-identified coupler, transport and chemistry classes. The three classes are fully segmented

164 and exchange information through interfaces. Segmentation ensures that any of the three

165 coupler, transport and chemistry classes can be replaced without modifications of any of the

166 two other ones. The solution of the reactive transport problem after spatial discretization

167 eventually consists in the temporal integration with the chosen OS technique, which

168 iteratively calls transport and geochemical solvers through interfaces (Figure 1, middle row).

169 This is the core of the simulation that we identify as the processing phase. It is generic and

170 does not require at run time any further specification of transport, reactivity and coupler

171 methods. Standard error management techniques are used to stop the algorithm when any of

172 the integration method of the three classes fails, stopping the running process and returning

173 adapted error messages. 


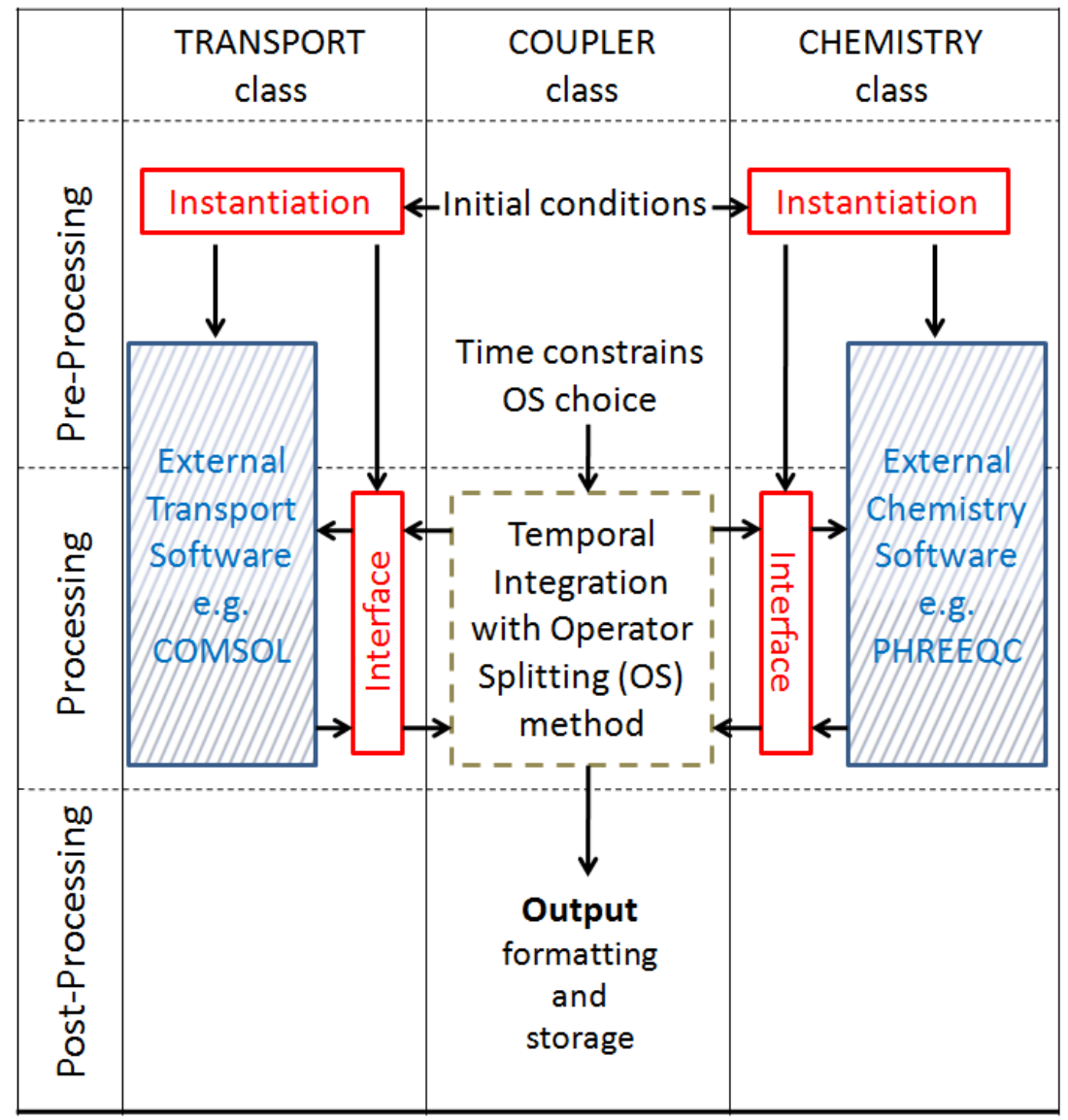

175 Figure 1: General software organization of TReacLab with the three coupler, transport and

176 chemistry classes in columns, and the three pre-processing, processing, and post-processing

177 phases in rows. Generic components represented in black are the organization and the

178 coupler class. External software for transport and chemistry are represented in blue with

179 hatched line (cannot be modified). Red boxes highlight the instantiation and interface

180 methods that must be developed when connecting new transport or chemistry software.

181 The processing phase can be generic because all specifications of the coupler, transport, and

182 chemistry classes are performed in a pre-processing phase (Figure 1, first row). The

183 pre-processing phase consists in the instantiation of the coupler, transport and chemical

184 classes, in the preparation of the interfaces that will transfer information and in the

185 specifications of the initial conditions. As detailed in Appendix B, instantiations are code

186 dependent. Instantiation can be done externally for example with the definition of a transport 
187 or chemical problem through the graphical user interface of software like COMSOL or

188 PHREEQC. It can also be done internally by a method within TReacLab specifying the inputs

189 and parameters to existing interfaces like IPhreeqc (Charlton and Parkhurst, 2011),

190 PhreeqcRM (Parkhurst and Wissmeier, 2015), or COMSOL livelink (COMSOL, 2010). Even

191 when instantiation is complex, it remains independent for each of the three classes.

192 Cross-dependencies and feedback between transport and reactivity like density-driven flows

193 with reacting species are not supported at this stage, although they may be important in some

194 applications like $\mathrm{CO}_{2}$ sequestration (Abarca et al., 2013).

195 Pre-processing phase specifies the initial conditions and transfers them to the coupler in

196 charge of starting the numerical integration. Post-processing is generic and only consists in

197 formatting and storing output concentrations and solver performances (Figure 1, bottom row).

198 Specifications are all restricted to the instantiation of the software and interface in the

199 pre-processing phase while processing and post-processing remain fully generic. Connections

200 between specific algorithms and generic structures are done by interfaces. Appendix B 201 provides a detailed description of the transport and chemistry classes, defining the interfaces 202 to the external codes.

\section{4. Examples and benchmarks}

204 The three following examples validate the methods and illustrate the implementation 205 presented in sections 2 and 3. The three of them are based on a 1D hydraulically 206 homogeneous system with steady-state flow and uniform dispersion (equation (2)). The 207 examples are compared visually against analytical solution or well-know numerical software. 208 Moreover, we show a convergence study for the first case being the reference solution the numerical solution with finest time resolution. 
210 The four examples display evolving degrees of complexity both in terms of chemical systems

211 and in terms of software called for transport and reactivity, software versions are given in

212 Table 1. The first example is a single-species transport with first-order decay. The transport

213 solver is COMSOL and the chemical solver is a simple analytical solution. This example is

214 used to assess the different coupling algorithms implemented and to check the implementation

215 of the interface with COMSOL. The second example is an equilibrium

216 precipitation/dissolution chemical system in a 1D hydraulically homogeneous system.

217 Chemical solver is IPhreeqc. Several solvers have been compared for the transport solver,

218 both to check IPhreeqc interface implementation and to evaluate the effect of the transport

219 solver. The third example is the most advanced in terms of chemistry. Chemical reactions are

220 partly in equilibrium and partly kinetically controlled. They involve precipitation and

221 dissolution reactions. The chemical code is PhreeqcRM. It is used in combination with

222 COMSOL as transport solver. The last problem face a 2D unsaturated system where transport

223 is modeled by Richards equation and solved by COMSOL. Chemistry is solved by

224 PhreeqcRM. These four test cases have been chosen to check the implementation and assess

225 the coupling methods developed. They are also simple enough from the development point of

226 view to be taken as starting points to model more advanced chemical systems and transport 227 conditions. 


\begin{tabular}{|c|c|}
\hline Software & Version \\
\hline MATLAB & R2013b \\
\hline COMSOL & $4.3 \mathrm{~b}$ \\
\hline PHREEQC & 3.3 .7 \\
\hline IPhreeqc & 3.3 .7 \\
\hline PhreeqcRM & 3.3 .9 \\
\hline
\end{tabular}

Table 1: Software versions.

\subsection{Single-species transport with first-order decay}

230 A single-species transport with first-order decay using different OS methods is compared to 231 an analytical solution (Van Genuchten and Alves, 1982). The reactive transport system

232 contains a single solute species of concentration $c$ :

$$
\frac{\partial c}{\partial t}=L(c)-k c
$$

233 where $L$ is given by equation (2). Equation (18) can straightforwardly be separated into

234 transport and chemistry operators corresponding to the two right-hand side terms.

235 At time 0 , the solute concentration is 0 in the domain $(c(x, t=0)=0)$. The concentration at the 236 left boundary is constant and equal to $1 \mathrm{~mol} / \mathrm{m}^{3}\left(c(x=0, t)=1 \mathrm{~mol} / \mathrm{m}^{3}\right)$. The boundary 237 condition on the right side of the domain is a perfectly absorbing condition $\left(c\left(x=x_{\max }, t\right)=0\right)$.

238 Parameters are derived from Steefel and MacQuarrie (1996) and given in Table 2. The solver 239 for transport is COMSOL and an analytical solution is used for the first-order decay. Solute 240 concentration progressively invades the domain from the left boundary with a smooth profile 241 resulting from the combination of dispersion and decay (Figure 2). Second-order methods 242 perform much better than first-order methods as expected. Errors are more pronounced at the 243 inlet boundary condition on the left side of the domain where the concentration is higher 
244 (Steefel and MacQuarrie, 1996; Valocchi and Malmstead, 1992). The sequential splitting

245 method with the transport operator performed first overestimates the amount of reaction for

246 the whole domain since it considers that all incoming solute is getting in without decay for the

247 full first time step. If the sequence of operators is exchanged, namely first chemistry is solved,

248 and then transport is solved, the amount of reaction is underestimated. The second-order

249 alternating splitting, which alternates between transport-chemistry and chemistry-transport

250 steps, shows strong improvement with compensations between overestimation in the first

251 application of the chemical operator and underestimation in the second application of the

252 chemical operator (Simpson and Landman, 2008; Valocchi and Malmstead, 1992).

\begin{tabular}{|cc|}
\hline Parameter & Value \\
$\boldsymbol{v}[\mathrm{m} / \mathrm{y}]$ & 100 \\
$D\left[\mathrm{~m}^{2} / \mathrm{y}\right]$ & 20 \\
$k\left[\mathrm{y}^{-1}\right]$ & 100 \\
$x_{\max }[\mathrm{m}]$ & 6 \\
$\Delta x[\mathrm{~m}]$ & 0.4 \\
$\Delta t[\mathrm{y}]$ & $410^{-3}$ \\
\hline
\end{tabular}

253 Table 2: Parameters for the single-species transport with first-order decay benchmark. $v$ is

254 the velocity, $D$ is the dispersion coefficient, $k$ is the decay rate, $x_{\max }$ is the length of the $1 D$

255 column, $\Delta x$ is the grid size, and $\Delta t$ is the time step. 

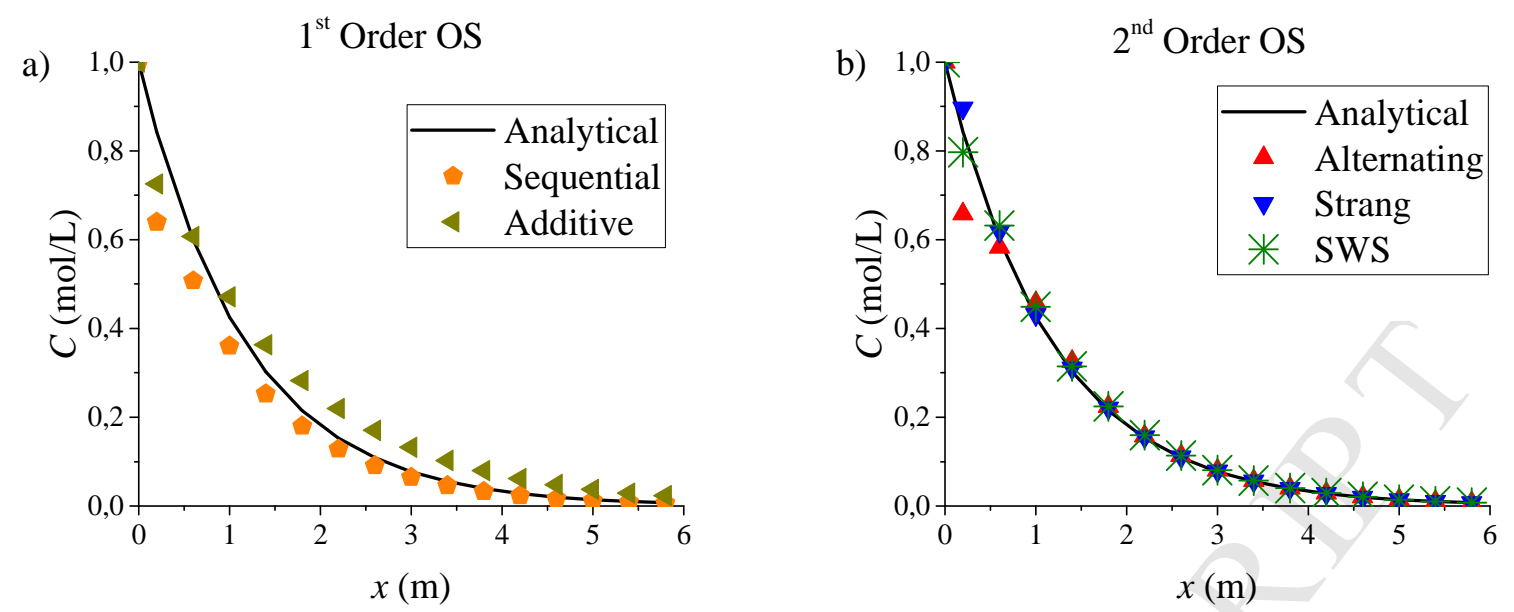

Figure 2: Comparison of first- and second-order OS for the single-species transport with

257 first-order decay at $t=0.5 y$. Parameters are given in Table 2. Analytical solution is derived 258 from Van Genuchten and Alves (1982).

259 The error at time $t=0.5 \mathrm{y}$ is taken as the quadratic relative difference over the domain of the 260 finest time step of the numerical solution and the numerical solutions for the corresponding 261 time step, $c_{N F}$ and $c_{N}$ respectively:

$$
\|e\|_{2}=\sqrt{\sum_{i=1}^{N_{z}}\left(\frac{s_{N F}^{i}(t)-s_{N}^{i}(t)}{d_{N F}(t)}\right)^{2}}
$$

262 Table 3 displays the values for evolving time steps and shows that all methods converge with

263 the time. The reference finest time step for each method has been $\Delta t=210^{-4} \mathrm{~s}$ (i.e. $c_{N F}^{i}(t)$

264 value). While all methods perform well, the sequential method is more accurate than the 265 additive one and second-order methods are overall more accurate than first-order methods. 266 The performance on convergence arranged on descending order is given by Strang, 267 symmetrically weighted splitting, alternating, sequential and additive. 


\begin{tabular}{|c|c|c|c|c|c|c|}
\cline { 3 - 7 } \multicolumn{2}{c|}{} & \multicolumn{2}{c|}{$\mathbf{1}^{\text {st }}$ order } & \multicolumn{3}{c|}{$\mathbf{2}^{\text {nd }}$ order } \\
\hline \multirow{2}{*}{} & $\Delta t(\mathrm{y})$ & Additive & Sequential & $\begin{array}{c}\text { Alternating } \\
\text { OS }\end{array}$ & Strang & SWS \\
\cline { 2 - 7 } \\
\cline { 2 - 7 } & $410^{-3}$ & 1,107 & 0,1667 & 0,075 & 0,032 & 0,049 \\
\cline { 2 - 7 } & $210^{-3}$ & 0,514 & 0,079 & 0,032 & 0,026 & 0,028 \\
\cline { 2 - 7 } & $410^{-4}$ & 0,114 & 0,019 & 0,029 & 0,031 & 0,029 \\
\hline
\end{tabular}

268 Table 3: Error $\|$ el $\|_{2}$ of equation (19) for the single-species transport with first-order decay

with different OS methods and splitting time steps.

270

271

272

273

274

275

276

277

\subsection{Calcite dissolution}

Calcite dissolution and dolomite formation has become a classical benchmark for reactive transport problems with sharp precipitation/dissolution fronts (Beyer et al., 2012; Engesgaard and Kipp, 1992; Prommer et al., 1999). Progressive introduction of magnesium calcium in a domain at equilibrium between calcium carbonate in solution and calcite $\left(\mathrm{CaCO}_{3}\right)$ dissolves the calcite and precipitates dolomite $\left(\mathrm{CaMg}\left(\mathrm{CO}_{3}\right)_{2}\right)$. This chemical system has been modeled with the physical and chemical parameters given by Table 4, Table 5, and Table 6. Chemical concentrations are initially homogeneous. At the initial time $(t=0)$, the chemical system is destabilized with the introduction of magnesium instead of calcium at the upper boundary condition $(x=0)$, inducing the dissolution/precipitation process. The boundary condition at the downstream limit $\left(x_{\max }\right)$ is a simple outflow of the solutes.

Here, we show how transport solvers can be applied and validate our interface to IPhreeqc. IPhreeqc performs the computation of components, aqueous speciation, precipitation and dissolution reactions (Charlton and Parkhurst, 2011). The database used is 'NAPSI_290502(260802).dat'. Transport is solved either with COMSOL Multiphysics (COMSOL, 2012), with a finite difference spatial discretization and forward Euler time 
286 integration, derived from built-in pdepe function of MATLAB (Skeel and Berzins, 1990).

287 Transport and chemistry are coupled through the simple sequential approach of equations 288 (A.1)-(A.3). PHREEQC is independently run as 1D reactive transport solver for general 289 comparison.

\begin{tabular}{|cc|}
\hline Parameter & Value \\
\hline$v[\mathrm{~m} / \mathrm{s}]$ & $10^{-5}$ \\
$D\left[\mathrm{~m}^{2} / \mathrm{s}\right]$ & $6.710^{-8}$ \\
$x_{\max }[\mathrm{m}]$ & 0.25 \\
$\Delta x[\mathrm{~m}]$ & 0.01 \\
$\Delta t[\mathrm{~s}]$ & 50 \\
\hline
\end{tabular}

290 Table 4: Physical parameters for the calcite dissolution benchmark. $v$ is the average velocity,

$291 D$ is the dispersion coefficient, $x_{\max }$ is the maximum length of the column, $\Delta x$ is the grid size, 292 and $\Delta t$ is the time step.

\begin{tabular}{|ccc|}
\hline $\begin{array}{c}\text { Chemical } \\
\text { Component and } \\
\text { Species }\end{array}$ & $\begin{array}{c}\text { Initial } \\
\text { value }\end{array}$ & $\begin{array}{c}\text { Boundary } \\
\text { value at } \\
\mathbf{x}=\mathbf{0}\end{array}$ \\
\hline $\mathrm{Ca}[\mathrm{mol} / \mathrm{L}]$ & $1.2310^{-4}$ & 0 \\
$\mathrm{C}[\mathrm{mol} / \mathrm{L}]$ & $1.2310^{-4}$ & 0 \\
$\mathrm{Cl}[\mathrm{mol} / \mathrm{L}]$ & 0 & $210^{-3}$ \\
$\mathrm{Mg}[\mathrm{mol} / \mathrm{L}]$ & 0 & $10^{-3}$ \\
$\mathrm{pH}[-]$ & 9.91 & 7 \\
$\mathrm{Calcite}[\mathrm{mol} / \mathrm{L}]$ & $210^{-4}$ & - \\
Dolomite $[\mathrm{mol} / \mathrm{L}]$ & 0 & - \\
\hline
\end{tabular}

293 Table 5: Calcite dissolution benchmark initial and boundary values for aqueous components 294 and mineral species. In PHREEQC, components are called elements. 


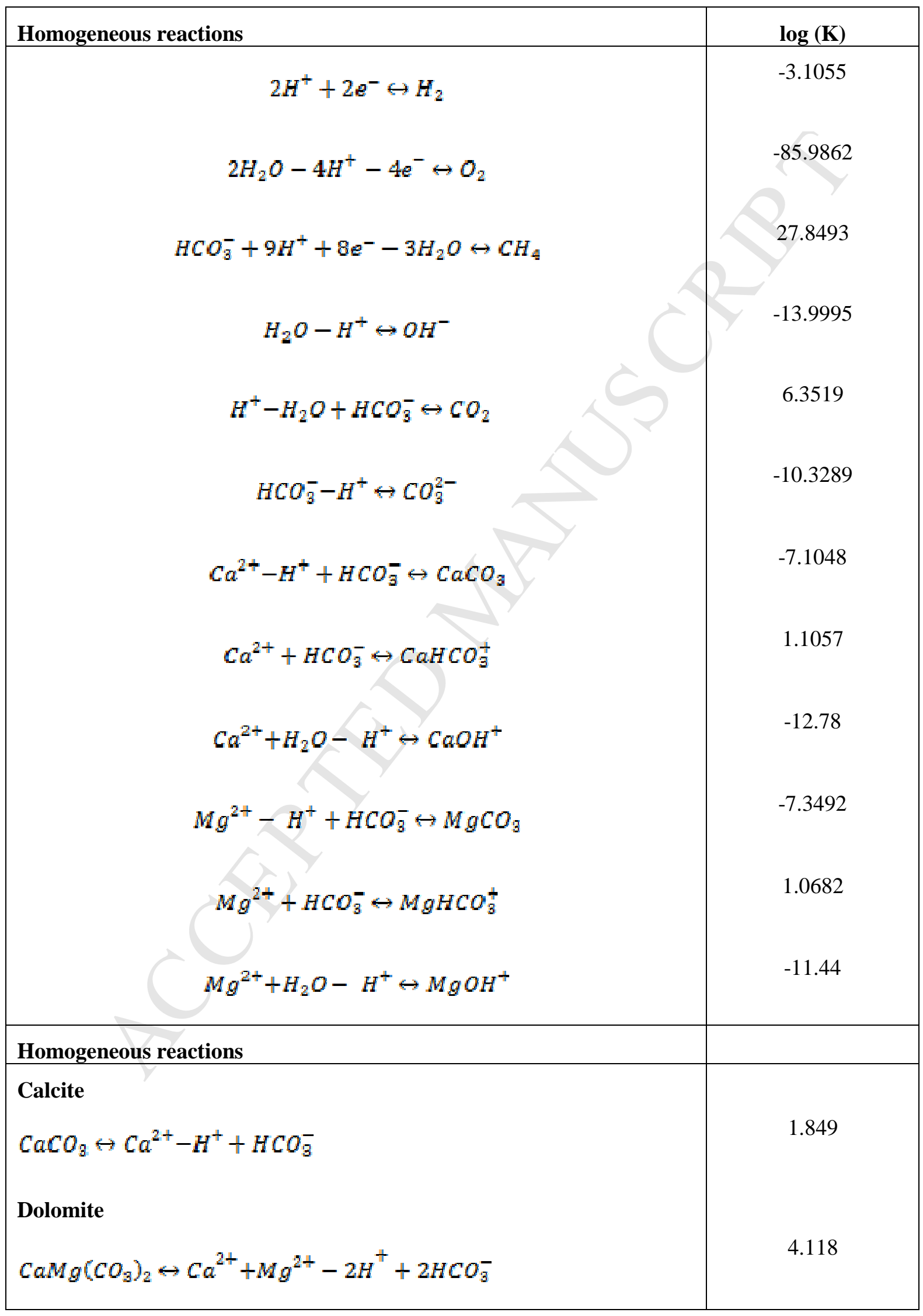


296 Table 6: Chemical system of the calcite dissolution benchmark. The upper part comprises the

297 homogeneous equations and the lower part the heterogeneous reactions. The first column

298 shows the equilibrium reactions and the second one the logarithms of equilibrium constants.

299 Figure 3 and Figure 4 display aqueous and mineral equivalent concentrations at time $t=10^{4} \mathrm{~s}$.

300 As magnesium and chloride get in the domain (Figure 3b and Figure 3d), calcite progressively

301 dissolves and is replaced by dolomite as expected (Figure 4). Some of the calcium remains in

302 solution and is flushed out (Figure 3a and Figure 3c). Because of the subsequent absence of

303 calcium in solution, dolomite dissolves again with some increase of calcium in solution

304 (Figure 3a and Figure 3c). The three different transport solvers give the same tendency as the 305 PHREEQC solution.
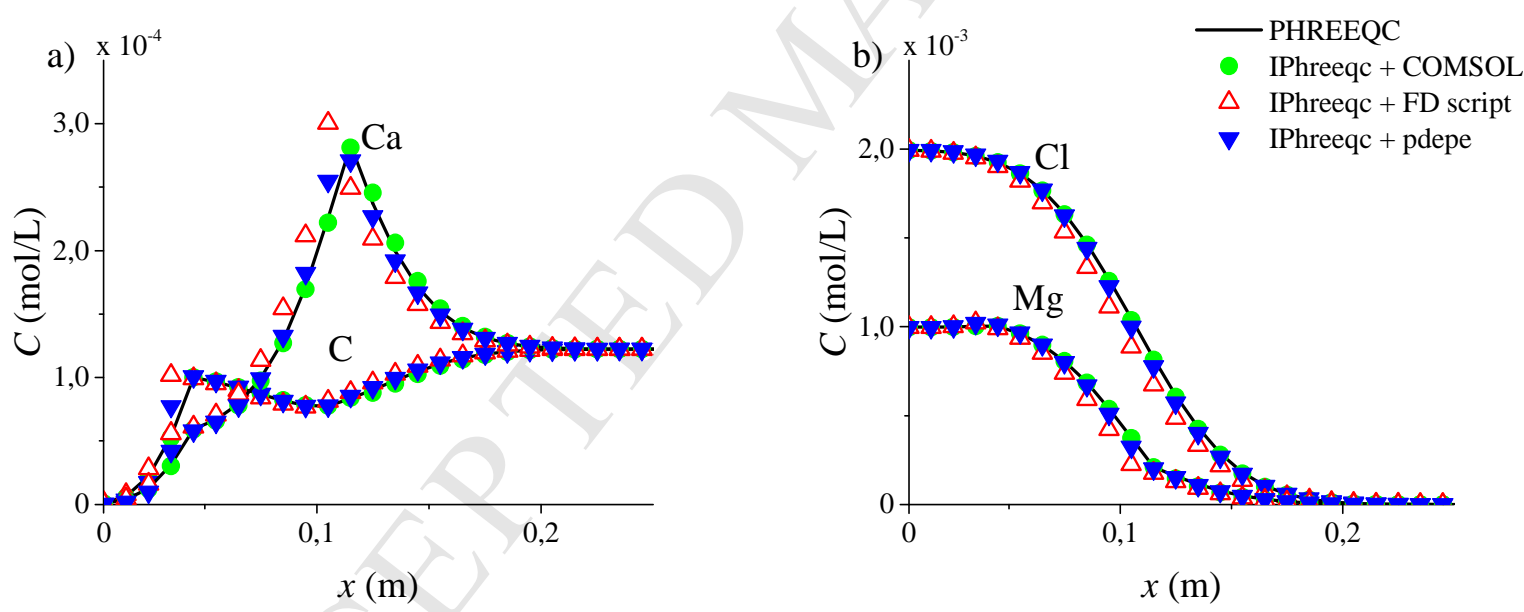

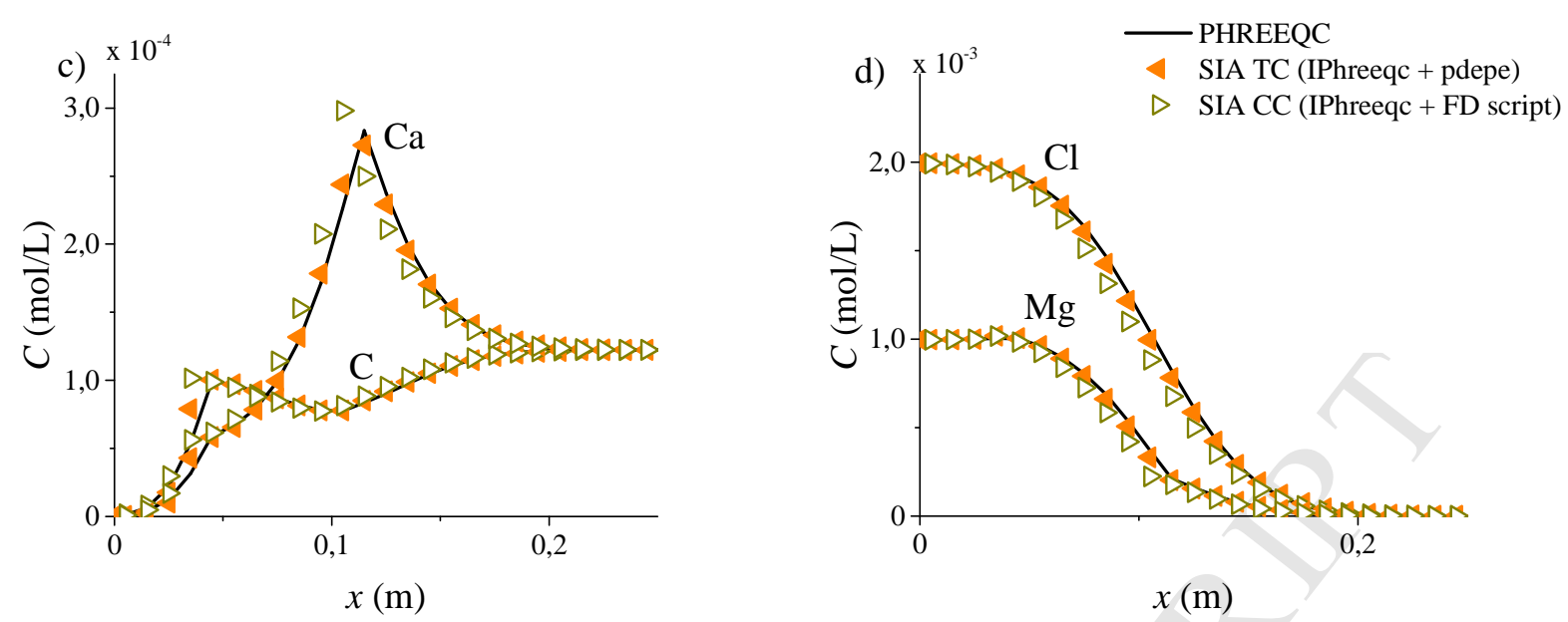

Figure 3: Aqueous concentration profiles at time $t=10^{4} \mathrm{~s}$.
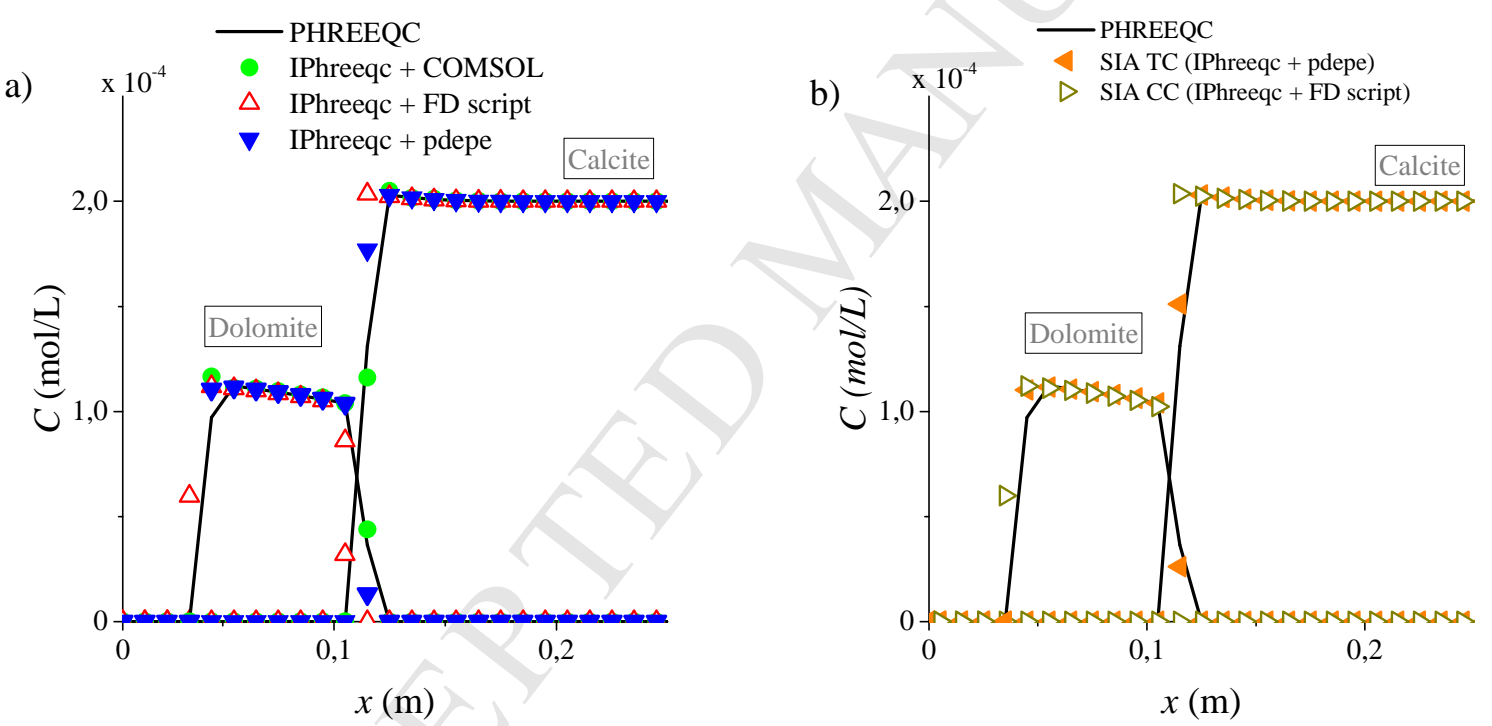

Figure 4: Dolomite and calcite equivalent concentration profiles with open and filled symbols

308 respectively at time $t=10^{4} \mathrm{~s}$.

309 Although COMSOL leads to good results, it is more than one order of magnitude slower than

310 the two other transport methods (Table 7). We checked that this large difference in

311 performances does not come from the numerical method but from the large time required for

312 COMSOL to start and stop when called numerous times externally. While this might not be 
313 an issue for large transport problems for which limitations will rather come from transport

314 operator, it is a constrain for smaller tests and benchmarks.

\begin{tabular}{|cc|}
\hline Software Coupling & Time \\
\hline IPhreeqc + COMSOL & $668 \mathrm{~s}$ \\
\hline IPhreeqc + FD script & $24 \mathrm{~s}$ \\
\hline IPhreeqc + pdepe & $40 \mathrm{~s}$ \\
\hline
\end{tabular}

315 Table 7: Time performance for the calcite dissolution benchmark using a sequential operator 316 splitting.

317 Whatever the coupling method, the consistency with PHREEQC is overall good. Although 318 COMSOL uses, as default, implicit time integration schemes for solving the transport 319 equation instead of the required explicit method, it still compares well with PHREEQC and 320 the other software couplings. Indeed, the sequential non iterative method requires an explicit 321 time integration for transport (equation (13)). It is not the case for COMSOL which uses (as 322 default) a backward differentiation formula temporal integration scheme, which order varies 323 with the internal time step adaptation (COMSOL, 2012). It thus introduces an additional error 324 in the coupling scheme (de Dieuleveult et al., 2009). However, by using such stable and 325 accurate temporal integrations, it enhances the robustness of the transport scheme.

\section{4.3. Mixed equilibrium-kinetic system}

327 We simulate the progressive increase of dissolved species in an atmospheric water infiltrating 328 a granitic bedrock. This test case is derived from Nardi et al. (2014). The hydraulic properties 329 of the system are found in Table 8. The infiltrating water has much lower concentrations of 330 dissolved species than the resident water. It interacts with five minerals (Table 9). It is in 331 equilibrium with calcite. The four other minerals k-feldspar, illite, albite and pyrite are subject 332 to kinetically controlled dissolution with rates ranging from $10^{-13}$ to $10^{-11} \mathrm{~mol} / \mathrm{s}$. All 
333 parameters and rate laws of the simulation are provided in the PHREEQC file of iCP (Nardi et al., 2014). The infiltrating water dissolves calcite to maintain equilibrium, increasing both the concentration of calcium and the $\mathrm{pH}$ of the solution. Other minerals also dissolve and increase

336 the concentrations of $\mathrm{Al}$ and $\mathrm{K}$ in solution, however at a much slower rate because of the 337 kinetic control of the reactions. $\mathrm{pH}$ is eventually buffered by the dissolution of illite and 338 pyrite.

\begin{tabular}{|cc|}
\hline Parameter & Value \\
\hline$v[\mathrm{~m} / \mathrm{s}]$ & $2.7810^{-6} \mathrm{~m} / \mathrm{s}$ \\
$D[\mathrm{~m} / \mathrm{s}]$ & $5.5510^{-9} \mathrm{~m}^{2} / \mathrm{s}$ \\
$x_{\max }[\mathrm{m}]$ & $0.08 \mathrm{~m}$ \\
$\Delta x[\mathrm{~m}]$ & $10^{-3} \mathrm{~m}$ \\
$\Delta t[\mathrm{~s}]$ & $720 \mathrm{~s}$ \\
\hline
\end{tabular}

339 Table 8: Parameters for mixed equilibrium-kinetic benchmark. $v$ is the average velocity, $D$ is

340 the dispersion coefficient, $x_{\max }$ is the maximum length of the column, $\Delta x$ is the grid size, and $341 \Delta t$ is the splitting time. 


\begin{tabular}{|c|c|c|}
\hline $\begin{array}{c}\text { Chemical } \\
\text { Component } \\
\text { and Species }\end{array}$ & $\begin{array}{l}\text { Initial } \\
\text { value }\end{array}$ & $\begin{array}{l}\text { Boundary } \\
\text { value }\end{array}$ \\
\hline $\mathrm{Ca}[\mathrm{mol} / \mathrm{L}]$ & $1.410^{-3}$ & $310^{-4}$ \\
\hline $\mathrm{C}[\mathrm{mol} / \mathrm{L}]$ & $4.910^{-3}$ & $1.910^{-4}$ \\
\hline $\mathrm{Cl}[\mathrm{mol} / \mathrm{L}]$ & $1.110^{-2}$ & $910^{-4}$ \\
\hline $\mathrm{Mg}[\mathrm{mol} / \mathrm{L}]$ & $7.410^{-4}$ & $210^{-4}$ \\
\hline $\mathrm{Mn}[\mathrm{mol} / \mathrm{L}]$ & $3.410^{-6}$ & 0 \\
\hline $\mathrm{S}[\mathrm{mol} / \mathrm{L}]$ & $9.610^{-4}$ & $4.810^{-4}$ \\
\hline $\mathrm{Na}[\mathrm{mol} / \mathrm{L}]$ & $1.310^{-2}$ & $310^{-4}$ \\
\hline $\mathrm{K}[\mathrm{mol} / \mathrm{L}]$ & $2.510^{-4}$ & $7.110^{-4}$ \\
\hline $\mathrm{Fe}[\mathrm{mol} / \mathrm{L}]$ & $7.210^{-6}$ & $5.410^{-5}$ \\
\hline $\mathrm{Sr}[\mathrm{mol} / \mathrm{L}]$ & 0 & $6.810^{-7}$ \\
\hline $\mathrm{Si}[\mathrm{mol} / \mathrm{L}]$ & $210^{-4}$ & $2.510^{-6}$ \\
\hline $\mathrm{Al}[\mathrm{mol} / \mathrm{L}]$ & $5.110^{-9}$ & $10^{-8}$ \\
\hline $\mathrm{P}[\mathrm{mol} / \mathrm{L}]$ & $3.810^{-6}$ & 0 \\
\hline $\mathrm{Br}[\mathrm{mol} / \mathrm{L}]$ & $1.710^{-5}$ & 0 \\
\hline $\mathrm{F}[\mathrm{mol} / \mathrm{L}]$ & $3.110^{-5}$ & $1.610^{-5}$ \\
\hline $\mathrm{pH}[-]$ & 7.5144 & 7.3 \\
\hline pe $[-]$ & -3.0836 & 13.6 \\
\hline $\begin{array}{l}\text { Calcite } \\
{[\mathrm{mol} / \mathrm{L}]}\end{array}$ & 6.065 & - \\
\hline $\begin{array}{c}\text { K-feldspar } \\
{[\mathrm{mol} / \mathrm{L}]}\end{array}$ & 0.239 & - \\
\hline Illite [mol/L] & 0.144 & - \\
\hline Albite $[\mathrm{mol} / \mathrm{L}]$ & 0.289 & - \\
\hline Pyrite [mol/L] & 1.17 & - \\
\hline
\end{tabular}

343 Table 9: Aqueous components and mineral species for mixed equilibrium-kinetic benchmark.

344 To simulate this set of reactions, we have chosen PhreeqcRM to assess the flexibility of

345 TReaCLab. Transport is simulated with COMSOL to benefit from the accurate transport 346 solver, it uses a variable order (between 1 and 5) backward differentiation formula. In the 
347 presence of both kinetically controlled and equilibrium reactions, both the quality of the

348 transport and reactive integrations and coupling issues may be critical. We choose a simple

349 sequential OS method with the successive integration of transport and reactivity. The results

350 obtained by the coupling of COMSOL and PhreeqcRM are close to the solution given by

351 PHREEQC alone for the dissolved species and kinetically dissolving minerals (Figure 5). The

352 time step of the coupled PhreeqcRM and COMSOL integration has been taken smaller than

353 the characteristic mesh scale transport time and reactive time at least for the kinetical reaction

354 to ensure accurate integrations. The most difficult quantity to get accurately is the calcium

355 concentration because calcite is at equilibrium. The time step must be reduced to recover a

356 steeper reactive front (Figure 6).

357 This more advanced test shows that the computational load should be well balanced between

358 the coupler, transport and chemistry methods. While coupling is the critical component in

359 cases of equilibrium reactions and may even require highly integrated coupling strategies like

360 global implicit methods (Hoffmann et al., 2010; Saaltink et al., 2001), it is not the case for

361 kinetically controlled reactions. In this case of mixed equilibrium kinetic reaction, elementary

362 coupling and accurate transport and reactive solvers can be efficient with small enough time

363 steps where sharp reaction fronts are involved. 

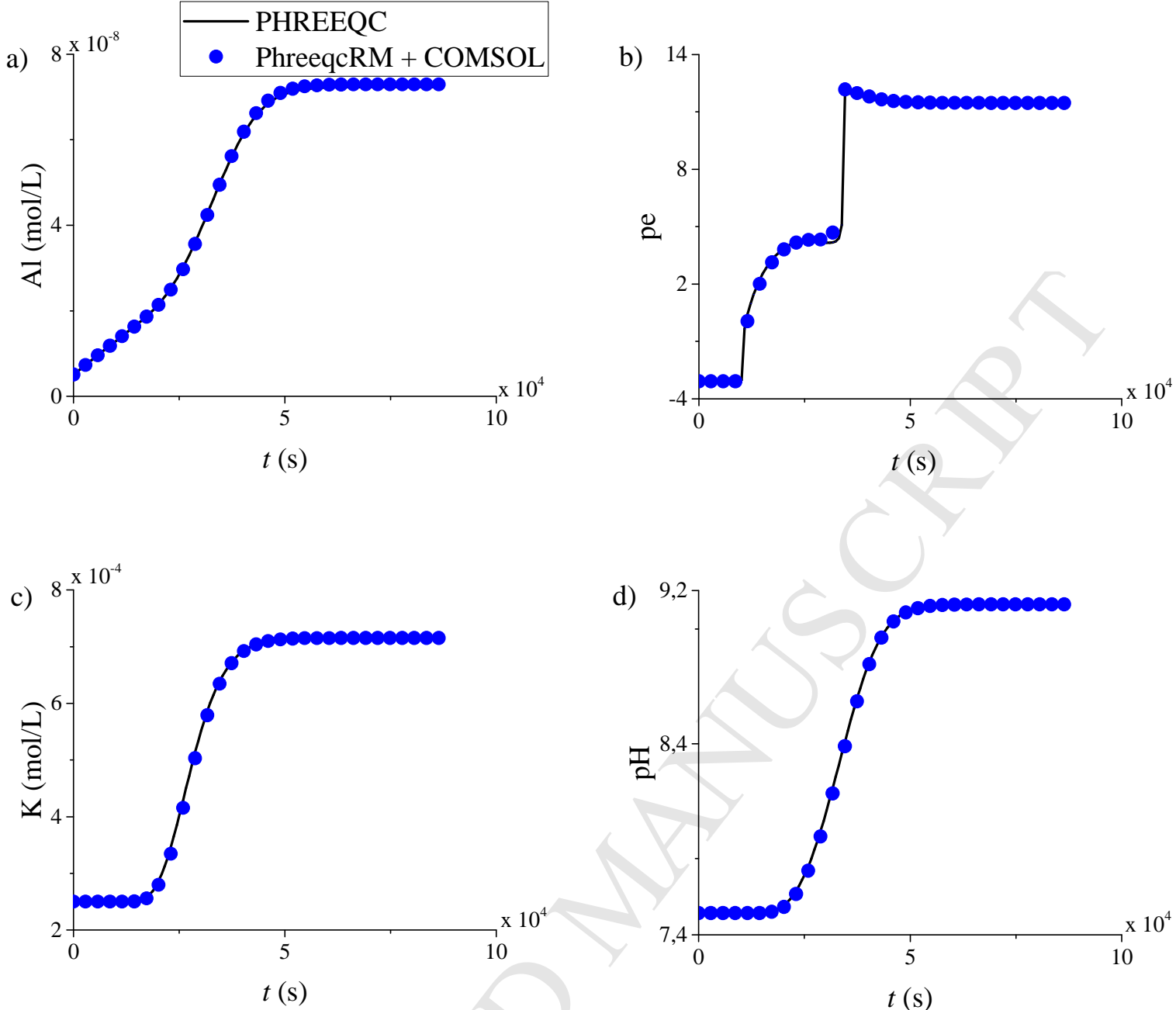

364 Figure 5: Comparison of results between the coupling of PhreeqcRM and COMSOL and 365 PHREEQC observed for the mixed equilibrium-kinetic benchmark at the output of the column. 


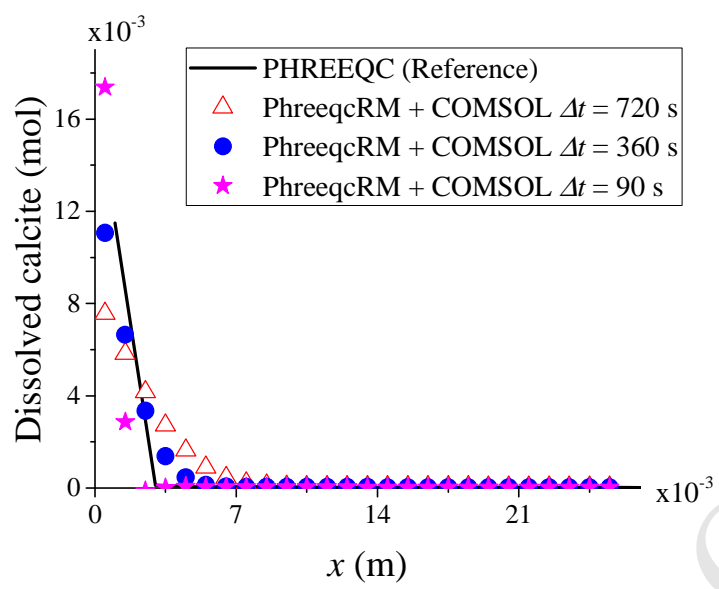

Figure 6: Quantity of dissolved calcite with PhreeqcRM and COMSOL for two different splitting time steps $\Delta t=720 \mathrm{~s}, 360 \mathrm{~s}$ and $90 \mathrm{~s}$. PHREEQC independently is used as reference.

\subsection{Pesticide infiltration}

371 The following benchmark concerns the infiltration in an unsaturated soil column of a

372 carbamate insecticide (Aldicarb) (MIKE(DHI), 2016; Multiphysics, 2008; Šimůnek et al., 373 1994; Wissmeier and Barry, 2011). The soil column is a 2D axisymmetric cylinder made up 374 of two layers with a smaller hydraulic conductivity in the upper layer but higher saturation.

375 Transport is modeled by Richards' equation and solved by COMSOL (Figure 7). Aldicarb is 376 transported downwards and sideways from the infiltration (top of the column from $r=0 \mathrm{~m}$ to $377 r=0.25 \mathrm{~m}$ ). Chemistry is described by first-order decay chain reactions (Figure 8), being only 378 mobile Aldicarb, Aldicarb sulfoxide and Aldicarb sulfone (i.e. the other species are fix 379 species). These system of ordinary differential equations is solved by PhreeqcRM. 


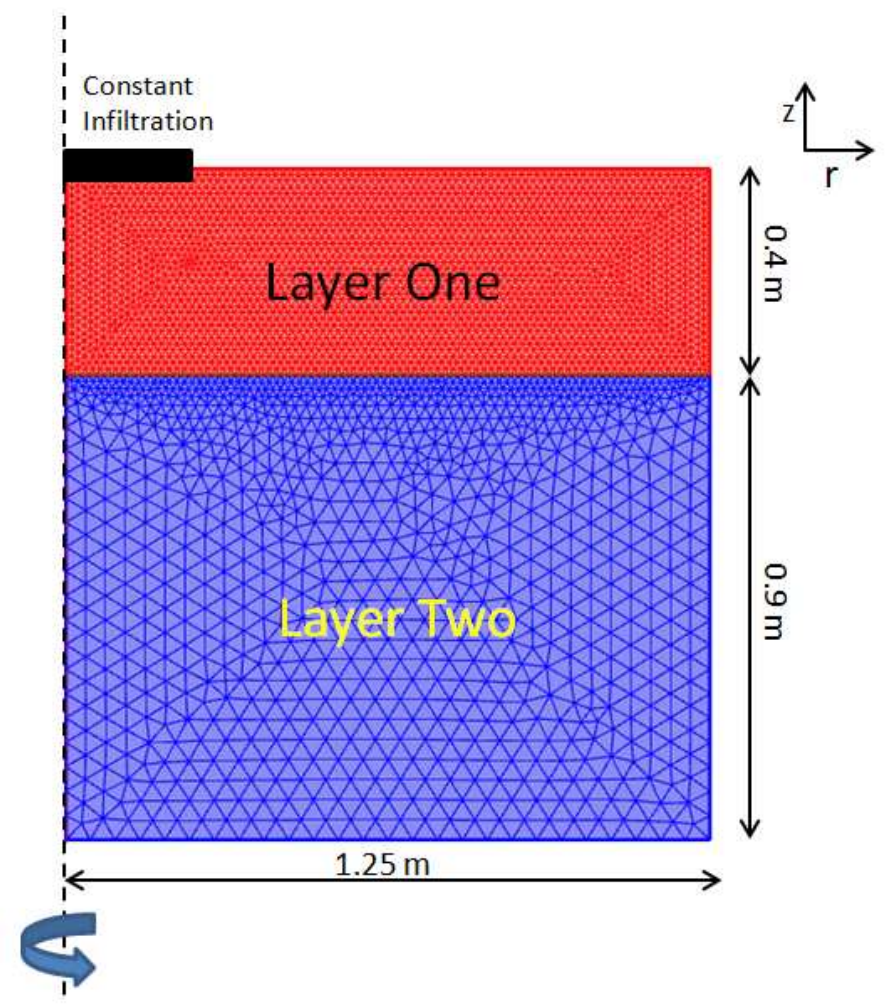

$381 \quad$ Figure 7: Soil column geometry and mesh.

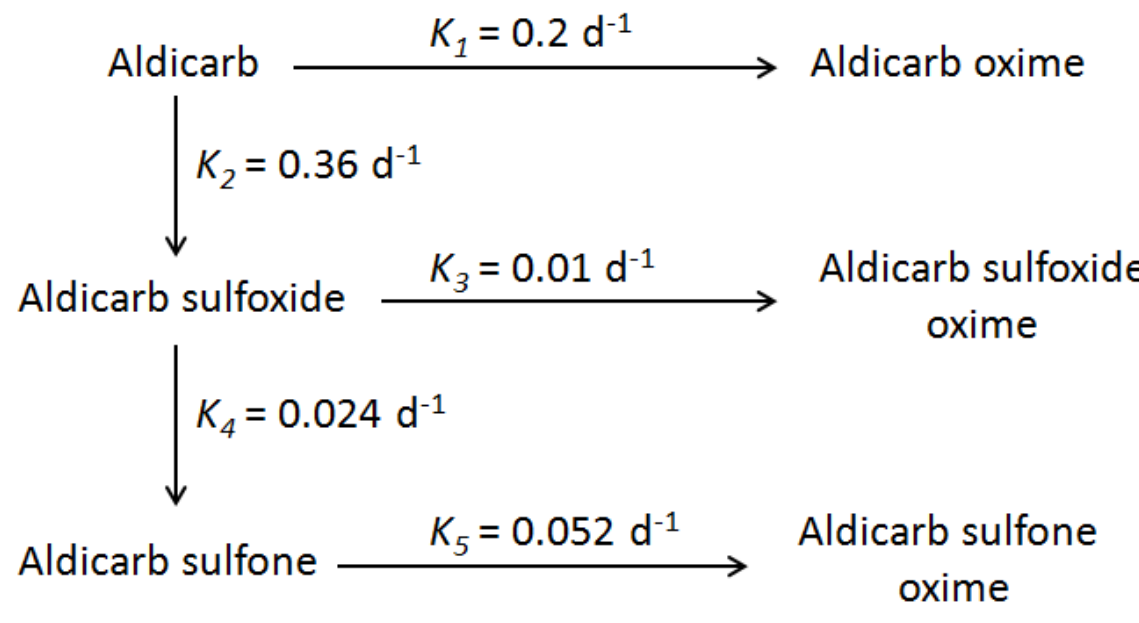

383 Figure 8:Aldicarb reaction chain. 
384 The simulation time is 8 days with a splitting time step of 0.05 days. The number of nodes is 3853936 nodes. Figure 9a and Figure 9b show the concentration in the soil column of Aldicarb 386 and Aldicarb sulfone, respectively. Aldicarb disappears fast from the domain since its kinetic 387 constant are fast in comparison to the kinetic constants of the daughter species. Therefore, 388 Aldicarb (and also Aldicarb oxime) are presented close to the infiltration condition. On the 389 contrary, the other daughter species (Aldicarb sulfoxide, aldicarb sulfone, aldicarb sulfoxide 390 oxime, aldicarb sulfone oxime) have a similar distribution in the domain. Figure 9c and 9d 391 show the concentration of Aldicarb and Aldicarb sulfone when $r=0 \mathrm{~m}$ for the different OS 392 methods and COMSOL alone. It is possible to see a good agrement between all the methods, 393 although a discrepancy between the methods and COMSOL is observable. The discrepancy is 394 related to the OS error and the chosen integration time scheme for the chemistry step. 

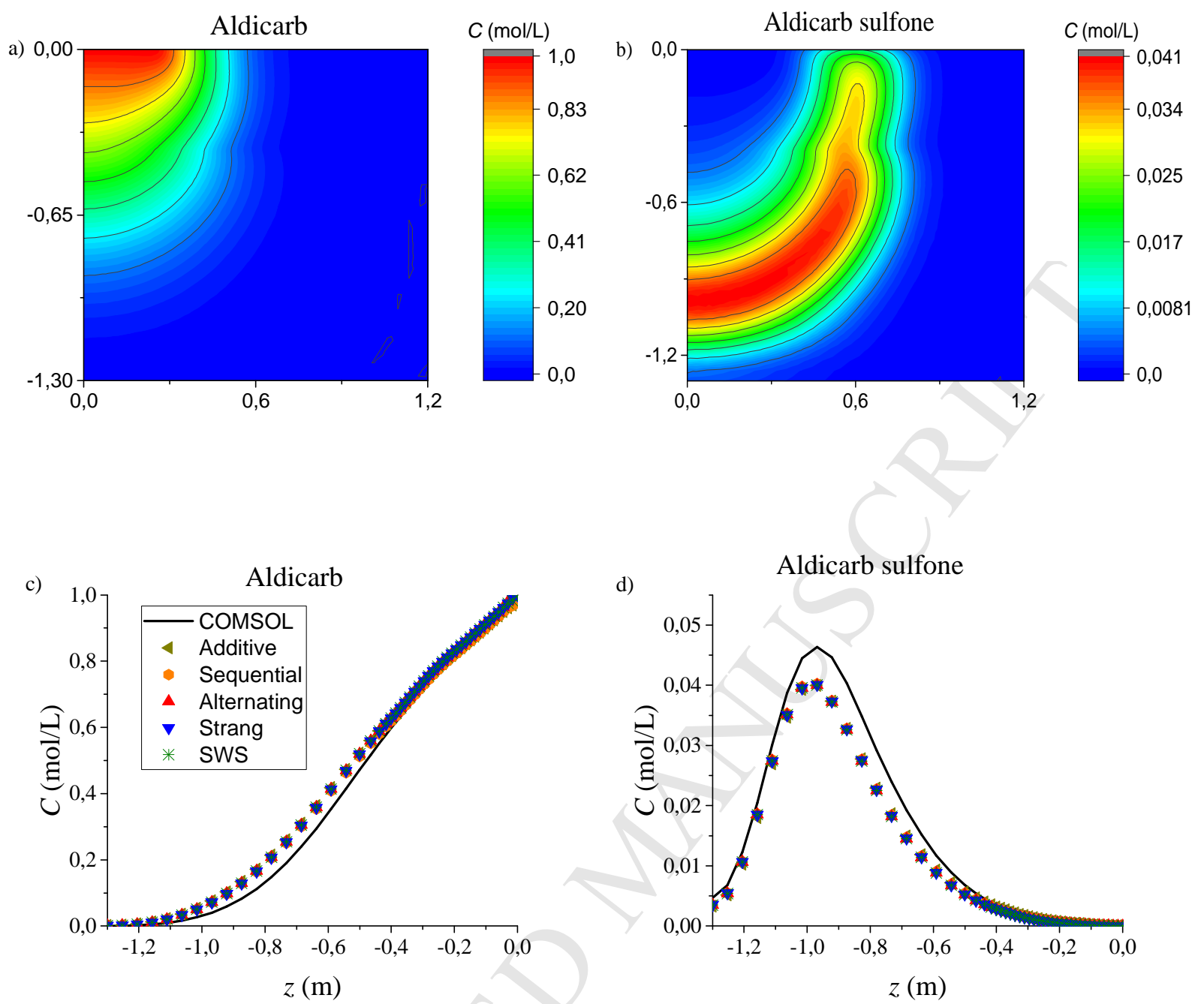

395 Figure 9: a) Aldicarb contour plot after 8 days, b) Aldicarb oxime contour plot after 8 days,

c) Concentration aldicarb at $r=0 \mathrm{~m}$ for all the methods and Comsol, d) Concentration

397 aldicarb oxime at $r=0 \mathrm{~m}$ for all the methods and Comsol.

\section{Discussion}

399 As shown by many previous studies and by the four examples of the previous section, reactive 400 transport problems can be solved by a wide diversity of transport, chemistry, and operator 401 splitting methods. No method is currently accepted as systematically more accurate and 402 efficient than any other. Integration of the transport and chemistry operators in PHREEQC using more appropriate splitting with advection-reaction on one side and diffusion-reaction on 
404 the other side leads to better resolution of chemical fronts as shown in the second and third 405 cases (Parkhurst and Appelo, 1999), but such front can be obtained by smaller time steps. It is 406 not only the integration but also the successive improvements of the methods that lead to 407 significantly more accurate schemes. TReacLab results remain however close, displaying the 408 same overall behavior both on solute and mineral concentrations. The interest of fully 409 segmented reactive transport implementations like in TReacLab is not motivated by the 410 accuracy and should not be used when other more integrated and optimized software are 411 appropriate and freely available.

412 Despite their lower accuracy, fully segmented implementations may be useful in situations 413 where flexibility is essential. It is the case when extensive modeling work has been performed 414 in independent software environments for transport or chemistry, and extensions to reactive 415 transport problems are required. Transport and chemistry solvers are then imposed and should 416 be coupled with as few specific developments as possible. For example, COMSOL and 417 PHREEQC have been interfaced here and in several other works because of their complementarity (Nardi et al., 2014; Nasir et al., 2014; Wissmeier and Barry, 2011). It is 419 possible to specify advanced geometrical configurations in COMSOL through a convenient 420 graphical user interface (Azad et al., 2016). PHREEQC provides advanced capacities for 421 modeling complex geochemical systems with extensive database of reactions (Charlton and 422 Parkhurst, 2011; Parkhurst and Wissmeier, 2015). In such cases, building the structure of the 423 model may be the first and dominant issue in developing simulation capacities. That is when 424 codes like TReacLab can provide practical bridges for reactive transport systems. The 425 examples of section 4 however shows that they must be used with great care. Especially, the 426 called software may have different temporal integration schemes than the explicit and implicit 427 methods required by the SNIA and SIA coupling methods as discussed for the higher-order 428 schemes of COMSOL in section 4. Using codes like COMSOL may enhance robustness at a 
certain cost of accuracy. Thus, implementation capacity does not guarantee validity. Validity must be carefully checked and argued with other comparable cases or with appropriate convergence analysis.

Another targeted use of TReacLab concerns the development and test of new coupling methods or strategies. Operator splitting can be performed with various methods including for example adaptative time stepping (Belfort et al., 2007; Gasda et al., 2011). Global implicit approaches that separate geochemical and transport software might also be more widely tested providing the Jacobian of the chemical operator and taking into account current limitations such as the difficulties to model precipitation/dissolution reactions (Amir and Kern, 2010). TReacLab may then be used as a platform where interfaces to chemical and transport operators are available and have been tested and documented for other coupling methods.

These applications are possible because TReacLab is a fully free and open software that can be directly accessed and downloaded (https://github.com/TReacLab/TReacLab). The free and open use of TReacLab has been dominant in its development and in the choices made for its organization. The repository thus provides two main directories with sources and examples respectively. Sources are organized in four main categories for chemistry, transport, coupler and utilitaries. At the root of the chemistry, transport and coupler directories are the virtual classes as main entries. Examples of instantiations are provided in the subdirectories. Additional developments may take advantage of the documented examples provided at the different levels of the software.

\section{Conclusion}

We provide in the TReacLab code a fully segmented implementation of the coupling of independent geochemical and transport software. Coupling is based on a general expression of 
452 the split-operator strategy with a set of classical methods. TReacLab should facilitate the

453 development of reactive transport simulation capacities for independent reactive and transport

454 software. Systematic comparison to the well-established PHREEQC model for uniform 1D

455 reactive transport cases shows a good agreement with TReacLab. Systematic comparison

456 against COMSOL for the 2D problem shows that full decoupling at the implementation level

457 has a cost in accuracy. Sharp dissolution fronts of thermodynamically controlled reactions

458 especially are generally smoothed in split-operator strategies. Steeper fronts might be

459 recovered with smaller splitting time steps at larger computational costs. Beyond the

460 implementation and the simulation capacity, consistency and validity of the numerical models

461 should be systematically assessed. TReacLab can be freely accessed and used to promote the

462 development of coupling methods and to provide additional modeling capacity for reactive

463 transport coupling in geological media.

\section{Appendix A: Implemented operator splitting methods}

465 We detail the mathematical formulation for the sequential splitting (Geiser, 2009) :

$$
\begin{array}{cc}
\frac{a z^{1}}{a t}=\mathcal{L}_{1} Z^{1}, & Z^{1}\left(x, t^{n}\right)=Z\left(x, t^{n}\right), \\
\frac{a z^{n}}{g t}=\mathcal{L}_{2} Z^{2}, & t^{n} \leq t \leq t^{n+1}, \\
Z^{2}\left(x, t^{n}\right)=Z^{1}\left(x, t^{n+1}\right), & t^{n} \leq t \leq t^{n+1}, \\
Z\left(x, t^{n+1}\right)=Z^{2}\left(x, t^{n+1}\right),
\end{array}
$$

466 the additive splitting (Faragó et al., 2008a; Faragó et al., 2008b) :

$$
\frac{\partial z^{1}}{\partial t}=\mathcal{L}_{1} Z^{1}, \quad Z^{1}\left(x, t^{n}\right)=Z\left(x, t^{n}\right), \quad t^{n} \leq t \leq t^{n+1}
$$




$$
\begin{gathered}
\frac{\partial z^{2}}{\partial t}=\mathcal{L}_{2} Z^{2}, \quad Z^{2}\left(x, t^{n}\right)=Z\left(x, t^{n}\right), \quad t^{n} \leq t \leq t^{n+1}, \\
Z\left(x, t^{n+1}\right)=Z^{1}\left(x, t^{n+1}\right)+Z^{2}\left(x_{v} t^{n+1}\right)-Z\left(x, t^{n}\right)
\end{gathered}
$$

467 the Strang splitting (Strang, 1968) :

$$
\begin{array}{cc}
\frac{a Z^{1}}{\partial t}=\mathcal{L}_{1} Z^{1}, & Z^{1}\left(x, t^{n}\right)=Z\left(x, t^{n}\right), \\
\frac{a z^{n}}{\partial t}=\mathcal{L}_{2} Z^{2}, & Z^{2}\left(x, t^{n}\right)=Z^{1}\left(x, t^{n+1 / 2}\right), t^{n+1 / 2}, \\
\frac{a z^{1}}{\partial t}=\mathcal{L}_{1} Z^{1}, & Z^{1}\left(x, t^{n+1 / 2}\right)=Z^{2}\left(x, t^{n+1}\right), \quad t^{n+1 / 2} \leq t \leq t^{n+1}, \\
Z\left(x, t^{n+1}\right)=Z^{1}\left(x, t^{n+1}\right),
\end{array}
$$


and the symmetrically weighted splitting (SWS) (Csomós et al., 2005) :

$$
\begin{array}{lcc}
\frac{\partial z^{1}}{\partial t}=\mathcal{L}_{1} Z^{1}, & Z^{1}\left(x, t^{n}\right)=Z\left(x, t^{n}\right), & t^{n} \leq t \leq t^{n+1}, \\
\frac{\partial z^{n}}{\partial t}=\mathcal{L}_{2} Z^{2}, & Z^{2}\left(x, t^{n}\right)=Z^{1}\left(x, t^{n+1}\right), & t^{n} \leq t \leq t^{n+1}, \\
\frac{\partial z^{2 *}}{\partial t}=\mathcal{L}_{2} Z^{2 *}, & Z^{2 *}\left(x, t^{n}\right)=Z\left(x, t^{n}\right), & t^{n} \leq t \leq t^{n+1}, \\
\frac{\partial z^{1 *}}{\partial t}=L_{1} Z^{1 *}, & Z^{1 *}\left(x, t^{n}\right)=Z^{2 *}\left(x, t^{n+1}\right), & t^{n} \leq t \leq t^{n+1}, \\
Z\left(x, t^{n+1}\right)=\frac{z^{2}\left(x, t^{n+1}\right)+z^{1+}\left(x, t^{n+1}\right)}{2} . &
\end{array}
$$

469 The alternating splitting algorithm (Valocchi and Malmstead, 1992) is based on a sequential

470 splitting. It is defined by two successive splitting time steps with a permutation of the operator 471 sequence between the splitting time steps.

\section{Appendix B: Complementary notes on software organization}

473 We successively describe the general toolbox organization, the coupler, transport and 474 chemistry classes. We concretely show how operator splitting methods can be introduced and 475 how other transport and geochemical codes can be connected.

\section{B.1 Coupling methods}

477 The coupler is at the center of TReacLab as it performs the temporal integration and calls the 478 transport and chemistry solvers through the OS algorithm. In the pre-processing phase, it gets 479 the initial conditions and the temporal constrains of the integration. It is also in charge of 
storing the required results before formatting and outputting them in the post-processing phase. Because the coupler is at the core of the toolbox, its methods remain generic. Interactions with the transport and chemistry solvers are also fully generic thanks to template interfaces calling external software and managing the exchange of information. Calling external software relies on the so-called Solve_Engine method for both transport and chemistry software. Solve_Engine takes as inputs the concentration data and the time step over which the integration must be performed. It returns the updated concentrations, a flag to check the success of the integration and an error message in case of failure to activate and inform the error management procedure mentioned in the former section. The coupler is based on a fixed structure of concentration data. Whatever the structure of concentrations in the transport and chemical codes, the structure of concentrations within the coupler is always the same. It consists in a matrix with in columns chemical species and in rows the position within the domain (Figure B.1). The size of the matrix is equal to the number of cells times the number of chemical species and components passed through the coupler. Chemical species include solutes and fixed species. As this is the sole link between the chemical code and the coupler also in charge of temporary results storage for the post-processing, it must transfer all quantities necessary for the algorithm and for the later extraction. The format of the matrix is set in the pre-processing phase and it is fixed for the whole simulation. TReacLab does not support yet any modification of species number to transfer between codes. Even if some solute species are absent over some time of the simulation, they will be transferred. This choice does not limit the capacity of the software as long as the chemical system is known from the beginning but might have some consequences on its performance in cases where solute composition strongly evolves. The choice of generality and flexibility, here like in other places, has a cost in efficiency. All modifications of concentration format are eventually performed in the interfaces between the coupler and the transport and chemistry solvers 


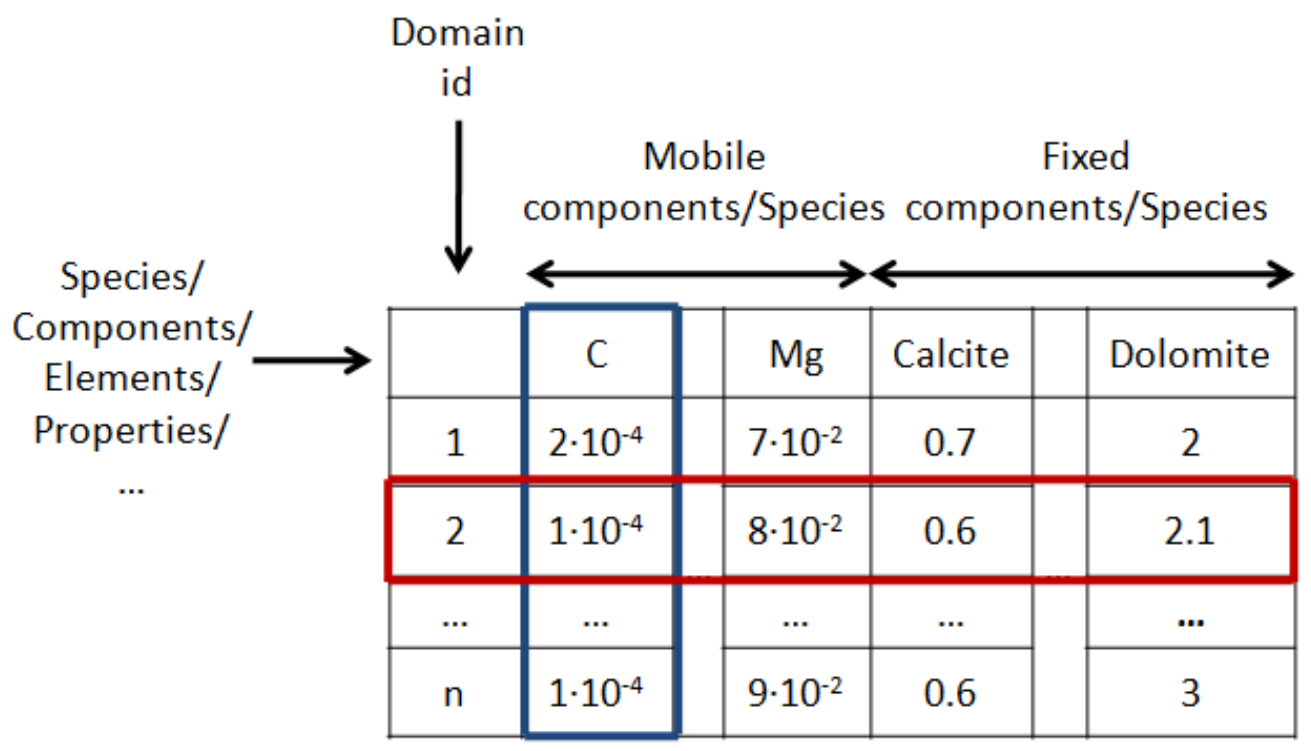

506

507 Figure B.1: Concentration format internal to the coupler class. To ensure generality, this structure of concentration is always the same and does not depend on the external transport and chemistry software. Species concentration are given in columns and are passed to the transport software as such. Concentrations at given locations are stored in rows with both mobile and fixed species. They are transferred either line per line or globally to the chemistry software. Fixed species are transferred from the chemistry code to the coupler to enable their possible use in the post-processing phase for results and outputs.

514 Thanks to the template methods calling the transport and chemical solvers and to the generic 515 concentration format, operator splitting methods can be simply implemented. These are not 516 more than a combination of simple calls of solvers passing and updating concentration 517 information. Several sequential non-iterative techniques have thus been implemented, as 518 detailed in section 2.3. 
519 Specifications of the coupler are thus the name of the coupling method necessary to switch to

520 the corresponding method in the coupler class, the temporal constrains of the integration and a

521 vector of additional parameters. Temporal constrains of the integration are not only the initial

522 and final times of the integration but also the times at which the solution must be stored. All

523 time related parameters are stored into a time class. Additional parameters may be tolerances

524 for example when using sequential iterative approaches. Instantiation of the coupler class thus

525 consists in providing the identifier of the chosen coupling technique, the time constrains in the

526 time class (initial time, final time, time to save the results, OS time step) and the additional

527 parameters possibly needed by the algorithm.

\section{B.2 Geochemical solver}

529 Geochemical codes widely differ by their principles, the type of reactivity they consider and

530 their input/output formats and parameters. We propose to normalize some of their interface to

531 simplify exchanges with the coupler. In any case of equilibrium or kinetic reactions or of a

532 mixed combination of them, geochemical codes steadily take concentrations, reaction

533 constants, rate parameters, reaction times, as inputs and return output concentrations. All

534 specifications linked to the choice of components, primary and secondary species should be

535 set in the geochemical code or in the interface so that the geochemical solver does not have to

536 be modified and the coupler remains generic. Whether components are used or not, the

537 definition of the chemical system is not unique. Even when components are used, several

538 alternative and reliable definitions can be chosen (Fang et al., 2003; Hoffmann et al., 2012;

539 Molins et al., 2004). Numerical and conceptual consistencies between the transport and

540 chemical systems should thus be ensured externally before any implementation.

541 While solute concentrations are instantiated by the coupler and systematically passed to the 542 geochemical solver, equilibrium and kinetic constants are considered as constant. They are 
543 defined once for all in the pre-processing phase. For example in PHREEQC, chemical

544 reactions and constants are already defined in databases like 'Phreeqc.dat' or 'llnl.dat'.

545 Initialization of mineral quantities is done at the beginning of the simulation when setting the

546 initial conditions through the coupler. The interface between the coupler and the geochemical

547 solver is made up of the Solve_Engine that calls the geochemical solver and the methods that

548 modify the concentration format. By default, the geochemical solver is instantiated and stored

549 for each of the nodes of the computational grid for the whole domain of the simulation. Any

550 data that are not passed to the coupler is, in general, kept in the instances of the geochemical

551 code. Another option is provided by software that allow simultaneous computations for

552 several independent batches like it is for example the case of PHREEQC. In such cases only

553 one instance of the geochemical solver is necessary. Exchanges of data between the coupler

554 and the geochemical solver are defined in the pre-processing phase and remain fixed for the

555 whole duration of the simulation. It is precisely at this stage that components are derived

556 through the algebraic operations of equation (6) and passed to the coupler. The coupler does

557 not manage the transformation of concentration and species but just their transfer between the

558 transport and geochemical solvers. The use of components does not fundamentally change the

559 calling sequence of the geochemical operator but modifies its interface to the coupler.

560 Components may be specified by the geochemical code like in PHREEQC or by the user in

561 the pre-processing phase by loading the matrix of $U$ (equation (6)). In this latter case,

562 components are defined by the user in the pre-processing phase and are computed by the

563 interface that adapts the information to be passed through the coupler to the transport solver.

564 Connection of a new geochemical code requires essentially four operations. First, a new

565 daughter class of the template chemistry class must be defined. It can be built up using, as

566 template, one of the examples provided and described in the section 4. Second, an interface

567 must be created to filter the required information given from the coupler to the Solve_Engine 
method. Third, an instantiation procedure should be provided whether it is internal or external

to TReacLab. Fourth, the template Solve_Engine calling function of the geochemical solver must be written and optionally tested before being effectively used in reactive transport 571 problems.

\section{B.3 Transport solver}

573 Despite the diversity of the transport mechanisms and numerical schemes to solve them, we

574 provide here a basic interface designed mostly to address transport in a generic way. As 575 previously stated, this approach assumes that transport parameters are not modified by the 576 species concentration. This absence of feedback currently precludes density driven flows as 577 well as permeability and porosity modifications due to precipitation or dissolution. TReacLab 578 might be extended in this direction on the basis of slow evolutions of porosity or density. The 579 transport operator relies on concentration independent parameters. We detail in the following 580 the interaction between the coupler and the transport classes with the exchange of data and the 581 instantiation of the transport solver. We will conclude this section with the development 582 required to connect other transport codes.

583 While geochemical codes operate on species concentration on a given computational node, 584 transport codes operate on a given species concentration over all the domain. In terms of data 585 structure, each of the columns of the concentration array are successively transferred to the 586 geochemical code and each of the rows (or linear combinations of rows) are given to the 587 transport code (Figure B.1). The transport operator is thus iteratively called for each of the 588 species or components explicitly specified in the interface between the coupler and the 589 transport solver (Figure 1). The time range over which temporal integration should be 590 performed and the identifiers of the transported species are also transferred to the transport 591 solver. Species identification is essential when considering species sensitive diffusion 
592 coefficient. The transport solver returns the updated concentration field at the final time of the

593 time range, an indicator of success or failure of the integration and a message to document

594 algorithm failures. The basic exchange of concentrations with the imposed integration times

595 are the sole requirements for the coupler to proceed.

596 All other parameters of the transport code should be set in the pre-processing phase, which

597 may become an important part of the eventual reactive transport code. In fact it does not cover 598 only the flow and transport parameters but more broadly the full structure of the domain, of 599 the computational grid, and of the boundary conditions. As for the geochemical code, the 600 transport code can be instantiated internally or externally. In case of internal definition, it 601 should contain at least the flow and transport properties, the morphology of the domain and 602 the structure of the computational grid (coordinates of the computational nodes). A default set 603 of classes is provided for 1D problems as templates for the morphology (domain definitions), 604 the computational grid (identification and coordinates of nodes and edges), the boundary 605 conditions (nature and values for boundary conditions) and the hydraulic and transport 606 properties. We recall as also said in section 2.2 that some operator splitting techniques might 607 impose limitations on the transport solver in terms of integration scheme or in terms of time 608 step (de Dieuleveult et al., 2009). Both the OS technique and the transport integration should 609 be chosen consistent.

610 Operations on the transport class are thus decomposed between the pre-processing and the 611 processing phases. Specifications of the operator with all necessary parameters is performed 612 in the pre-processing phase. Only generic exchanges of concentrations are needed in the 613 processing phase. Additional information would generally be needed externally to identify the 614 location of the computational nodes. More advanced information from the definition of the 615 domain, parameters and boundary conditions will be generally defined in the transport code 
616 rather than in TReacLab. For example, Comsol or Modflow have their own grid definitions.

617 They are complete and efficient. It may be straightforwardly extracted and cross-referenced

618 with the results of TReacLab as long as the cell numbers correspond, a basic but necessary

619 requirement. This choice is motivated by both the generality and the simplicity of TReacLab.

620 It also highlights that TReacLab remains a coupler that transfers information and does not

621 process in any way the relation of concentrations between cells like a transport operator does.

622 The methodological choice of handling the spatial dimension of the problem within the

623 transport operator is not only operational. It is also ensuring the capacity to connect a wide

624 range of transport codes with their own logic and structure. For example, the multi-physics

625 software COMSOL has its own mesh generator methods and internal structures that should

626 not be duplicated in TReacLab but interfaced. Connecting other codes would thus require

627 reduced work as long as they can already be called from the same environment of

628 development (here MATLAB) on a discretized time basis. More in details, any new transport

629 code would require: 1) the development of the main calling function Solve_Engine to call it

630 from the coupler 2) the adaptation of the concentration format in the interface methods that

631 match the concentrations to the internal data structure of the external code, 3) the instantiation

632 of the transport class and 4) the access to the coordinates of the computational nodes for

633 outputs purposes. As for the geochemical code, implementation of the interface should be

634 checked before any full reactive transport coupling. This can be completed within TReacLab

635 by using an idle process instead of the geochemical code.

636 Acknowledgements: We acknowledge ANDRA and the ANR project H2MNO4 under the 637 number ANR-12-MONU0012-01 for their financial support, Jocelyne Erhel and David L.

638 Parkhurst for constant and fruitful discussions, and Javier Molinero for initial exchanges. 


\section{REFERENCES}

641

642

643

644

645

646

647

648

649

650

651

652

653

654

655

656

657

658

659

660

Abarca, E., Nardi, A., Grandia, F., Molinero, J., 2013. Feedback between reactive transport and convective flow during $\mathrm{CO} 2$ migration in a saline aquifer, EGU General Assembly Conference Abstracts, p. 7707.

Amir, L., Kern, M., 2010. A global method for coupling transport with chemistry in heterogeneous porous media. Computational Geosciences 14, 465-481.

Apoung-Kamga, J.-B., Have, P., Houot, J., Kern, M., Semin, A., 2009. Reactive Transport in Porous Media. ESAIM: Proceedings 28, 227 - 245.

Azad, V.J., Li, C., Verba, C., Ideker, J.H., Isgor, O.B., 2016. A COMSOL-GEMS interface for modeling coupled reactive-transport geochemical processes. Computers \& Geosciences 92, 79-89.

Barry, D.A., Miller, C.T., Culligan-Hensley, P.J., 1996. Temporal discretisation errors in noniterative split-operator approaches to solving chemical reaction/groundwater transport models. Journal of Contaminant Hydrology 22, 1-17.

Bea, S.A., Carrera, J., Ayora, C., Batlle, F., Saaltink, M.W., 2009. CHEPROO: A Fortran 90 object-oriented module to solve chemical processes in Earth Science models. Computers \& Geosciences 35, 1098-1112.

Bear, J., 1972. Dynamics of fluids in porous media. Elsevier, New York.

Belfort, B., Carrayrou, J., Lehmann, F., 2007. Implementation of Richardson extrapolation in an efficient adaptive time stepping method: applications to reactive transport and unsaturated flow in porous media. Transport in Porous Media 69, 123-138. 
661 Bethke, C.M., 2007. Geochemical and biogeochemical reaction modeling. Cambridge $662 \quad$ University Press.

663 Beyer, C., Li, D., De Lucia, M., Kühn, M., Bauer, S., 2012. Modelling CO2-induced fluid664 rock interactions in the Altensalzwedel gas reservoir. Part II: coupled reactive transport simulation. Environmental Earth Sciences 67, 573-588.

666

667

668

669

670

671

672

673

674

675

676

677

678

679

680

681

682

Carrayrou, J., Mosé, R., Behra, P., 2004. Operator-splitting procedures for reactive transport and comparison of mass balance errors. Journal of Contaminant Hydrology 68, 239268.

Charlton, S.R., Parkhurst, D.L., 2011. Modules based on the geochemical model PHREEQC for use in scripting and programming languages. Computers \& Geosciences 37, 1653 1663.

Clement, T.P., Sun, Y., Hooker, B.S., Petersen, J.N., 1998. Modeling Multispecies Reactive Transport in Ground Water. Ground Water Monitoring \& Remediation 18, 79-92.

Commend, S., Zimmermann, T., 2001. Object-oriented nonlinear finite element programming: a primer. Advances in Engineering Software 32, 611-628.

COMSOL, A., 2010. COMSOL Multiphysics-LiveLink for Matlab User's Guide, comsol 4.1 edition.

COMSOL, A., 2012. 4.3 User's Guide. Comsol.

Csomós, P., Faragó, I., 2008. Error analysis of the numerical solution of split differential equations. Mathematical and Computer Modelling 48, 1090-1106.

Csomós, P., Faragó, I., Havasi, Á., 2005. Weighted sequential splittings and their analysis. Computers \& Mathematics with Applications 50, 1017-1031. 
683 de Dieuleveult, C., Erhel, J., 2010. A global approach to reactive transport: application to the 684 MoMas benchmark. Computational Geosciences 14, 451-464.

685 de Dieuleveult, C., Erhel, J., Kern, M., 2009. A global strategy for solving reactive transport 686 equations. Journal of Computational Physics 228, 6395-6410.

687 Diersch, H.-J.G., 1996. Interactive, graphics-based finite-element simulation system 688 FEFLOW for modeling groundwater flow, contaminant mass and heat transport 689 processes. WASY Institute for Water Resource Planning and System Research Ltd., $690 \quad$ Berlin, Germany.

691 Engesgaard, P., Kipp, K.L., 1992. A geochemical transport model for redox-controlled 692 693 movement of mineral fronts in groundwater flow systems: A case of nitrate removal by oxidation of pyrite. Water Resources Research 28, 2829-2843.

694 Fang, Y., Yeh, G.-T., Burgos, W.D., 2003. A general paradigm to model reaction-based 695 biogeochemical processes in batch systems. Water Resources Research 39, 1083.

696 Faragó, I., Gnandt, B., Havasi, Á., 2008a. Additive and iterative operator splitting methods 697 698 and their numerical investigation. Computers \& Mathematics with Applications 55, 2266-2279.

Faragó, I., Thomsen, P.G., Zlatev, Z., 2008b. On the additive splitting procedures and their computer realization. Applied Mathematical Modelling 32, 1552-1569.

701 Friedly, J.C., Rubin, J., 1992. Solute transport with multiple equilibrium-controlled or 702 kinetically controlled chemical reactions. Water Resources Research 28, 1935-1953.

703 Gasda, S.E., Farthing, M.W., Kees, C.E., Miller, C.T., 2011. Adaptive split-operator methods 704 for modeling transport phenomena in porous medium systems. Advances in Water 705 Resources 34, 1268-1282. 
Geiser, J., 2009. Decomposition methods for differential equations: theory and applications. CRC Press.

708

Hammond, G., Lichtner, P., Lu, C., Mills, R., 2012. Pflotran: reactive flow \& transport code for use on laptops to leadership-class supercomputers. Groundwater reactive transport models, 141-159.

Hammond, G.E., Lichtner, P.C., Mills, R.T., 2014. Evaluating the performance of parallel subsurface simulators: An illustrative example with PFLOTRAN. Water Resources Research 50, 208-228.

Hoffmann, J., Kräutle, S., Knabner, P., 2010. A parallel global-implicit 2-D solver for reactive transport problems in porous media based on a reduction scheme and its application to the MoMaS benchmark problem. Computational Geosciences 14, 421-433.

Hoffmann, J., Kräutle, S., Knabner, P., 2012. A general reduction scheme for reactive transport in porous media. Computational Geosciences 16, 1081-1099.

Hundsdorfer, W., Verwer, J.G., 2013. Numerical solution of time-dependent advectiondiffusion-reaction equations. Springer Science \& Business Media.

Kazemi Nia Korrani, A., Sepehrnoori, K., Delshad, M., 2015. Coupling IPhreeqc with UTCHEM to model reactive flow and transport. Computers \& Geosciences 82, 152 169.

Kazemi Nia Korrani, A., Sepehrnoori, K., Delshad, M., 2016. A Mechanistic Integrated Geochemical and Chemical-Flooding Tool for Alkaline/Surfactant/Polymer Floods. SPE Journal 21, 32-54. 
Kool, J., Van Genuchten, M.T., 1991. Hydrus: One-dimensional Variably Saturated Flow and Transport Model, Including Hysteresis and Root Water Uptake; Version 3.3. US Salinity Laboratory.

Kräutle, S., Knabner, P., 2005. A new numerical reduction scheme for fully coupled multicomponent transport-reaction problems in porous media. Water Resources Research 41, W09414.

Kulik, D.A., Wagner, T., Dmytrieva, S.V., Kosakowski, G., Hingerl, F.F., Chudnenko, K.V., Berner, U.R., 2013. GEM-Selektor geochemical modeling package: revised algorithm and GEMS3K numerical kernel for coupled simulation codes. Computational Geosciences 17, 1-24.

Lie, K., 2014. An introduction to reservoir simulation using MATLAB: User guide for the Matlab reservoir simulation toolbox (MRST), SINTEF ICT, Department of Applied Mathematics, Oslo, Norway.

Liu, J., Ewing, R.E., 2005. An Operator Splitting Method for Nonlinear Reactive Transport Equations and Its Implementation Based on DLL and COM, In: Zhang, W., Tong, W., Chen, Z., Glowinski, R. (Eds.), Current Trends in High Performance Computing and Its Applications: Proceedings of the International Conference on High Performance Computing and Applications, August 8-10, 2004, Shanghai, P.R. China. Springer Berlin Heidelberg, Berlin, Heidelberg, pp. 93-102.

Marty, N.C.M., Munier, I., Gaucher, E.C., Tournassat, C., Gaboreau, S., Vong, C.Q., Giffaut, E., Cochepin, B., Claret, F., 2014. Simulation of Cement/Clay Interactions: Feedback on the Increasing Complexity of Modelling Strategies. Transport in Porous Media 104, $385-405$. 
Mayer, K., 2000. MIN3P V1. 0 User Guide. University of Waterloo, Department of Earth Sciences 26.

752

McDonald, M.G., Harbaugh, A.W., 1988. A modular three-dimensional finite-difference ground-water flow model, In: Survey, U.S.G. (Ed.), Denver, Colorado.

MIKE(DHI), 2016. piChem: A FEFLOW Plugin for Advanced Geochemical Reactions, User Guide.

Molins, S., Carrera, J., Ayora, C., Saaltink, M.W., 2004. A formulation for decoupling components in reactive transport problems. Water Resources Research 40, W10301.

Morel, F.M., Hering, J.G., 1993. Principles and applications of aquatic chemistry. John Wiley \& Sons.

Multiphysics, C., 2008. Pesticide transport and reaction in soil. Earth Science Module Model Library.

Muniruzzaman, M., Rolle, M., 2016. Modeling multicomponent ionic transport in groundwater with IPhreeqc coupling: Electrostatic interactions and geochemical reactions in homogeneous and heterogeneous domains. Advances in Water Resources $98,1-15$.

Nardi, A., Idiart, A., Trinchero, P., de Vries, L.M., Molinero, J., 2014. Interface COMSOLPHREEQC (iCP), an efficient numerical framework for the solution of coupled multiphysics and geochemistry. Computers \& Geosciences 69, 10-21.

Nasir, O., Fall, M., Evgin, E., 2014. A simulator for modeling of porosity and permeability changes in near field sedimentary host rocks for nuclear waste under climate change influences. Tunnelling and Underground Space Technology 42, 122-135. 
772 Parkhurst, D.L., Appelo, C., 1999. User's guide to PHREEQC (Version 2): A computer

773

774

775

776 program for speciation, batch-reaction, one-dimensional transport, and inverse geochemical calculations.

Parkhurst, D.L., Kipp, K.L., Engesgaard, P., Charlton, S.R., 2004. PHAST, a program for simulating ground-waterflow, solute transport, and multicomponent geochemical reactions. USGS Techniques and Methods 6, A8.

Parkhurst, D.L., Wissmeier, L., 2015. PhreeqcRM: A reaction module for transport simulators based on the geochemical model PHREEQC. Advances in Water Resources 83, 176189.

Patel, R., Perko, J., Jacques, D., De Schutter, G., Ye, G., Van Breugel, K., 2013. Lattice Boltzmann based multicomponent reactive transport model coupled with geochemical solver for scale simulations, 5th International Conference on Computational Methods for Coupled Problems in Science and Engineering. International Center for Numerical Methods in Engineering (CIMNE), pp. 806-817.

Peterson, S., Hostetler, C., Deutsch, W., Cowan, C., 1987. MINTEQ user's manual. Pacific Northwest Lab., Richland, WA (USA); Nuclear Regulatory Commission, Washington, DC (USA). Div. of Waste Management.

Prommer, H., Davis, G., Barry, D., 1999. PHT3D—A three-dimensional biogeochemical transport model for modelling natural and enhanced remediation. Contaminated Site Remediation: Challenges Posed by Urban and Industrial Contaminants. Centre for Groundwater Studies, Fremantle, Western Australia, 351-358.

Pruess, K., Oldenburg, C., Moridis, G., 1999. TOUGH2 user's guide version 2. Lawrence Berkeley National Laboratory.

Register, A.H., 2007. A guide to MATLAB object-oriented programming. CRC Press. 
Rouson, D., Xia, J., Xu, X., 2011. Scientific software design: the object-oriented way. Cambridge University Press.

Saaltink, M.W., Ayora, C., Carrera, J., 1998. A mathematical formulation for reactive transport that eliminates mineral concentrations. Water Resources Research 34, 16491656.

Saaltink, M.W., Carrera, J., Ayora, C., 2001. On the behavior of approaches to simulate reactive transport. Journal of Contaminant Hydrology 48, 213-235.

Saaltink, M.W., Yakirevich, A., Carrera, J., Ayora, C., 2011. Fluid flow, solute and heat transport equations. Geochemical Modeling of Groundwater, Vadose and Geothermal Systems, 83.

Simpson, M.J., Landman, K.A., 2008. Theoretical analysis and physical interpretation of temporal truncation errors in operator split algorithms. Mathematics and Computers in Simulation 77, 9-21.

Šimůnek, J., Jacques, D., Van Genuchten, M.T., Mallants, D., 2006. Multicomponent geochemical transport modeling using HYDRUS-1D and HP1. J. Am. Water Resour. Assoc 42, 1537-1547.

Šimůnek, J., Vogel, T., Van Genuchten, M.T., 1994. The SWMS-2D code for simulating water and solute transport in two dimensional variably saturated media-Version 1.2. Research Report 132, US Salinity Lab., Agric. Res. Serv. USDA, Riverside, California, USA.

Skeel, R.D., Berzins, M., 1990. A method for the spatial discretization of parabolic equations in one space variable. SIAM journal on scientific and statistical computing 11, 1-32. 
818 Steefel, C., 2009. CrunchFlow software for modeling multicomponent reactive flow and transport. User's manual. Earth Sciences Division. Lawrence Berkeley, National Laboratory, Berkeley, CA. October, 12-91.

821

Steefel, C.I., DePaolo, D.J., Lichtner, P.C., 2005. Reactive transport modeling: An essential tool and a new research approach for the Earth sciences. Earth and Planetary Science Letters 240, 539-558.

Steefel, C.I., MacQuarrie, K.T., 1996. Approaches to modeling of reactive transport in porous media. Reviews in Mineralogy and Geochemistry 34, 85-129.

Strang, G., 1968. On the construction and comparison of difference schemes. SIAM Journal on Numerical Analysis 5, 506-517.

Thouvenot, P., Bildstein, O., Munier, I., Cochepin, B., Poyet, S., Bourbon, X., Treille, E., 2013. Modeling of concrete carbonation in deep geological disposal of intermediate level waste, EPJ Web of Conferences. EDP Sciences, p. 05004.

Trotignon, L., Devallois, V., Peycelon, H., Tiffreau, C., Bourbon, X., 2007. Predicting the long term durability of concrete engineered barriers in a geological repository for radioactive waste. Physics and Chemistry of the Earth, Parts A/B/C 32, 259-274.

Valocchi, A.J., Malmstead, M., 1992. Accuracy of operator splitting for advection-dispersionreaction problems. Water Resources Research 28, 1471-1476.

Van der Lee, J., 2002. CHESS Software for Geochemistry. Hydrology and Environmental Science, École des Mines de Paris, Fontainebleau, France.

van der Lee, J., De Windt, L., Lagneau, V., Goblet, P., 2003. Module-oriented modeling of reactive transport with HYTEC. Computers \& Geosciences 29, 265-275. 
840 Van Genuchten, M.T., Alves, W., 1982. Analytical solutions of the one-dimensional 841 convective-dispersive solute transport equation. United States Department of $842 \quad$ Agriculture, Economic Research Service.

843 Wissmeier, L., Barry, D.A., 2011. Simulation tool for variably saturated flow with 844 comprehensive geochemical reactions in two- and three-dimensional domains. $845 \quad$ Environmental Modelling \& Software 26, 210-218.

846 Yeh, G.T., Tripathi, V.S., 1989. A critical evaluation of recent developments in 847 hydrogeochemical transport models of reactive multichemical components. Water $848 \quad$ Resources Research 25, 93-108.

849 Zhang, F., 2012. Groundwater reactive transport models. Bentham Science Publishers.

850 Zheng, C., Wang, P.P., 1999. MT3DMS: a modular three-dimensional multispecies transport 851 model for simulation of advection, dispersion, and chemical reactions of contaminants 852 in groundwater systems; documentation and user's guide. DTIC Document. 


\section{Highlights}

- Object-oriented implementation of non-intrusive couplings for reactive transport

- Validation for 3 equilibrium and kinetically controlled 1D cases with PhreeqC and one 2D case with COMSOL.

- Illustration of implementation flexibility with different transport and reaction codes 